\title{
GOVERNANÇA NA COLETA SELETIVA DE RESÍDUOS SÓLIDOS URBANOS: MAPEAMENTO DOS ATORES PRESENTES NO MUNICÍPIO DE SÃO PAULO
}

\author{
Erica Aparhyan STELLA ${ }^{1}$ \\ Isabela Ribeiro Borges de CARVALHO² \\ Kelly Danielly da Silva Alcantara FRATTA ${ }^{3}$ \\ Lilian Ferreira dos Santos LACERDA ${ }^{4}$ \\ Luciana Aparecida Iotti ZIGLIO 5 \\ Sylmara Lopes Francelino GONÇALVES-DIAS ${ }^{6}$
}

RESUMO: Os estudos sobre a governança da coleta seletiva de resíduos sólidos urbanos nas cidades brasileiras e, especialmente, na Macrometrópole Paulista registram lacunas, reforçando a necessidade de estudos neste campo. Sendo assim, este artigo tem por

\footnotetext{
1 Fundação Getulio Vargas (FGV) - Escola de Administração de Empresas de São Paulo, São Paulo - SP - Brasil. Doutoranda em Administração Pública e Governo. Universidade de São Paulo (USP) - Escola de Artes, Ciências e Humanidades, São Paulo - SP - Brasil. Mestre em Gestão de Políticas Públicas. ORCID: https://orcid.org/00000003-4712-2542. erica.stella@usp.br.

2 Universidade de São Paulo (USP) - Programa de Pós-Graduação em Ciência Ambiental, São Paulo - SP Brasil. Doutoranda em Ciência Ambiental. Pesquisadora no Núcleo de Pesquisa em Organizações, Sociedade e Sustentabilidade (NOSS/USP). Universidade Federal do Rio Grande (FURG-RS) - Rio Grande - RS - Brasil. Mestre em Gerenciamento Costeiro. Oceanóloga. ORCID: https://orcid.org/0000-0002-4977-789. isabelarbc@usp.br.

3 Universidade Federal do ABC (UFABC) - Programa de Pós Graduação em Energia, Santo André - SP - Brasil. Doutoranda em Energia. ORCID: https://orcid.org/0000-0001-6081-4274. kelly.alcantara@ufabc.edu.br.

4 Universidade de São Paulo (USP) - Escola de Artes, Ciências e Humanidades, São Paulo - SP - Brasil. Mestre em Gestão de Políticas Públicas. ORCID: https://orcid.org/0000-0003-0985-0848. lilianfesa@alumni.usp.br.

5 Universidade de São Paulo (USP) - Escola de Artes, Ciências e Humanidades, São Paulo - SP - Brasil. Pós-doutora. Doutora em Geografia Humana. ORCID: https://orcid.org/0000-0002-3753-6859. 1ziglio@alumni.usp.br.

6 Universidade de São Paulo (USP) - Escola de Artes, Ciências e Humanidades, São Paulo - SP - Brasil. Professora Associada. Credenciada pelo Programa de Pós Graduação em Ciência Ambiental do Instituto de Energia e Ambiente (PROCAM-IEE) e pelo Programa de Pós Graduação em Sustentabilidade EACH/USP. Doutora em Ciências Ambientais (PROCAM. USP). Fundação Getúlio Vargas (FGV) - Escola de Administração de Empresas de São Paulo, São Paulo - SP - Brasil. Doutora em Administração. ORCID: https://orcid.org/0000-0001-6326-2129. sgdias@usp.br.
} 
objetivo caracterizar os atores e relaçóes presentes na governança da coleta seletiva de resíduos sólidos urbanos no município de São Paulo. Foram utilizadas revisão de literatura de fontes secundárias, pesquisa documental e tecnologias de software para a construção do mapa de atores como estratégia metodológica. Entre os resultados, foram identificados grupos de atores e seus vínculos na governança da coleta seletiva do município de São Paulo, expostos no mapa "Atores e relaçóes de governança na coleta seletiva no município de São Paulo". Nesse contexto, este estudo revelou que o elemento relacional do padrão de governança da coleta seletiva pode ser caracterizado como uma ampla rede de atores diversos, vagamente centrada no tecido relacional do Estado.

PALAVRAS-CHAVE: coleta seletiva de resíduos sólidos; governança; mapa de atores; São Paulo.

\title{
THE GOVERNANCE OF SELECTIVE WASTE COLLECTION OF MUNICIPAL SOLID WASTE: MAPPING THE ACTORS OF THE MUNICIPALITY OF SÃO PAULO
}

\begin{abstract}
Studies on the governance of selective collection of municipal solid waste in Brazilian cities and especially in the São Paulo macro-metropolis still have gaps, reinforcing the need for more research in this field. This article aims to present the actors and relations that comprise the governance of selective collection of municipal solid waste in the municipality of São Paulo. As a methodological strategy, this study made use of literature review from secondary sources, documentary research and software technology to build a map of actors. As a result, groups of actors and their connections who compose the governance structure of selective collection in the municipality of Säo Paulo have been identified, and they were presented on the map called "Governance Actors and relations within the Selective Collection Framework of the Municipality of São Paulo". In this context, this study revealed that the relational element of the governance pattern of selective collection can be characterized as a wide network of diverse actors, loosely centered on the relational fabric of the State.
\end{abstract}

KEYWORDS: selective solid waste collection; governance; map of actors; São Paulo.

\section{- Introdução}

Nas últimas décadas, foram realizadas pesquisas sobre governança, apontando que o conceito é polissêmico, o que resulta em um desafio à sua aplicação. 
Um problema que surge na busca pela definição do conceito de governança para os Estados é a legitimaçáo de que os atores podem agir para além das esferas regulatórias, em espaços de representação que se tornam arenas políticas (ROMÃO, 2010).

Por sua vez, os estudos sobre a macrometrópole paulista (MMP) partem de diversas perspectivas e enfoques, como infraestrutura, saneamento, educação e saúde, e bem-estar. Segundo Torres, Ramos e Pollachi (2020, p.108), a MMP "tem São Paulo por centro irradiador", cidade caracterizada por uma economia dinâmica, baseada em indústria, comércio e serviços, bem como em atividades financeiras, tecnológicas, informacionais e de comunicação. É possível compreender a MMP como fenômeno metropolitano e, mais ainda, como categoria norteadora dos "instrumentos das políticas públicas de desenvolvimento regional do governo estadual, como relevante escala para o planejamento e a governança" (TORRES; RAMOS; POLLACHI, 2020, p.109).

Dada a importância da MMP e a complexidade de sua governança; os desafios da gestão e gerenciamento dos resíduos sólidos urbanos (RSU); a relevância socioambiental da coleta seletiva e as lacunas observadas na literatura, torna-se necessário e oportuno o desenvolvimento de estudos que tragam um olhar direcionado para a cidade de São Paulo, dada a sua relevância na MMP. Assim, apresenta-se neste artigo um mapa dos diversos atores que constituem a governança na coleta seletiva na cidade de São Paulo.

Quando tratam de associar as definiçóes de governança com a gestão da coleta seletiva de RSU nas cidades brasileiras, esses desafios permanecem, registrando-se lacunas e reforçando a necessidade de estudos neste campo. Por exemplo, Moreira et al. (2019) pesquisaram sobre os riscos associados aos trabalhadores em centrais de triagem de materiais recicláveis em São Paulo, enquanto Rutkowski (2013) investigou redes solidárias de catadores de materiais recicláveis. Godoy (2016) examinou o mercado de limpeza urbana no município, ao passo que Klein, Gonçalves-Dias e Olivieri (2020) analisaram as transferências voluntárias federais para São Paulo em resíduos sólidos e Leite e Lócco (2020) articularam a análise de políticas públicas para discutir o papel político de uma rede de atores oriundos da comunidade epistêmica de resíduos sólidos. Por fim, Conke e Nascimento (2018) abordaram a dificuldade da gestão de dados dos programas de coleta seletiva.

Deste modo, argumenta-se a importância dos estudos sobre atores e governança da coleta seletiva de RSU nas cidades brasileiras e, especialmente, em São Paulo. Para que o conceito de governança seja utilizado para o estudo dos Estados e de suas açóes, ele deve ser redefinido no sentido de incorporar açóes 
boas e ruins dos governos, incorporar instituiçôes, atores e redes de relaçóes formais e informais que os unem (MARQUES, 2013).

Sendo assim, este artigo tem por objetivo caracterizar os atores presentes na governança da coleta seletiva de resíduos sólidos urbanos de São Paulo. As relaçôes entre os atores foram representadas em um mapa elaborado a partir do levantamento documental dos principais instrumentos da política de gestão de resíduos sólidos do município.

A finalidade do artigo foi responder às seguintes questôes: quem são os atores que compóem a governança da coleta seletiva de RSU na cidade de São Paulo? Quais são as relaçóes que esses atores estabelecem entre si? Para respondê-las, o artigo está estruturado em cinco seçôes, além desta introdução. Inicialmente, são apresentadas as estratégias metodológicas; os apontamentos sobre governança urbana; depois, os aspectos da coleta seletiva no município de Sáo Paulo e o contexto da MMP; seguido das discussóes e resultados; e consideraçôes finais.

Os resultados mostram o mapeamento dos atores e suas relaçôes na governança da coleta seletiva. Além disso, foi possível especificar novos grupos de atores da governança, além dos grupos propostos por Marques (2013). Especialmente, o mapa de atores resultante dá destaque a três atores que apresentam maior relevância na governança da coleta seletiva de São Paulo em função da quantidade e diversidade das suas relaçóes: as cooperativas de catadores, os munícipes-usuários e a Autoridade Municipal de Limpeza Urbana (AMLURB).

\section{Estratégias metodológicas}

O artigo tem como objeto empírico a governança da coleta seletiva na cidade de São Paulo. Como este estudo é fruto de um diagnóstico (GONÇALVESDIAS et al., 2020), foi estabelecido como recorte temporal de análise o ano de 2019. As principais técnicas de levantamento de dados utilizadas neste artigo foram análise documental (MOREIRA, 2005; CELLARD, 2008), seguida pela utilização do software Gephi para a elaboração do mapa de atores.

Além disso, foi realizada uma revisão narrativa da literatura relevante, conforme Paré et al. (2013) e UNESP (2015). A revisão de literatura narrativa é aquela que "não utiliza critérios explícitos e sistemáticos para a busca e análise crítica da literatura” (UNESP, 2015), de modo que os conceitos de governança, MMP e sistema da coleta seletiva de RSU foram selecionados e interpretados a partir da triangulação de dados secundários. Em seguida, foi construído o mapa de atores conforme as etapas mostradas na Fig. 1. 
Figura 1 - Etapas metodológicas

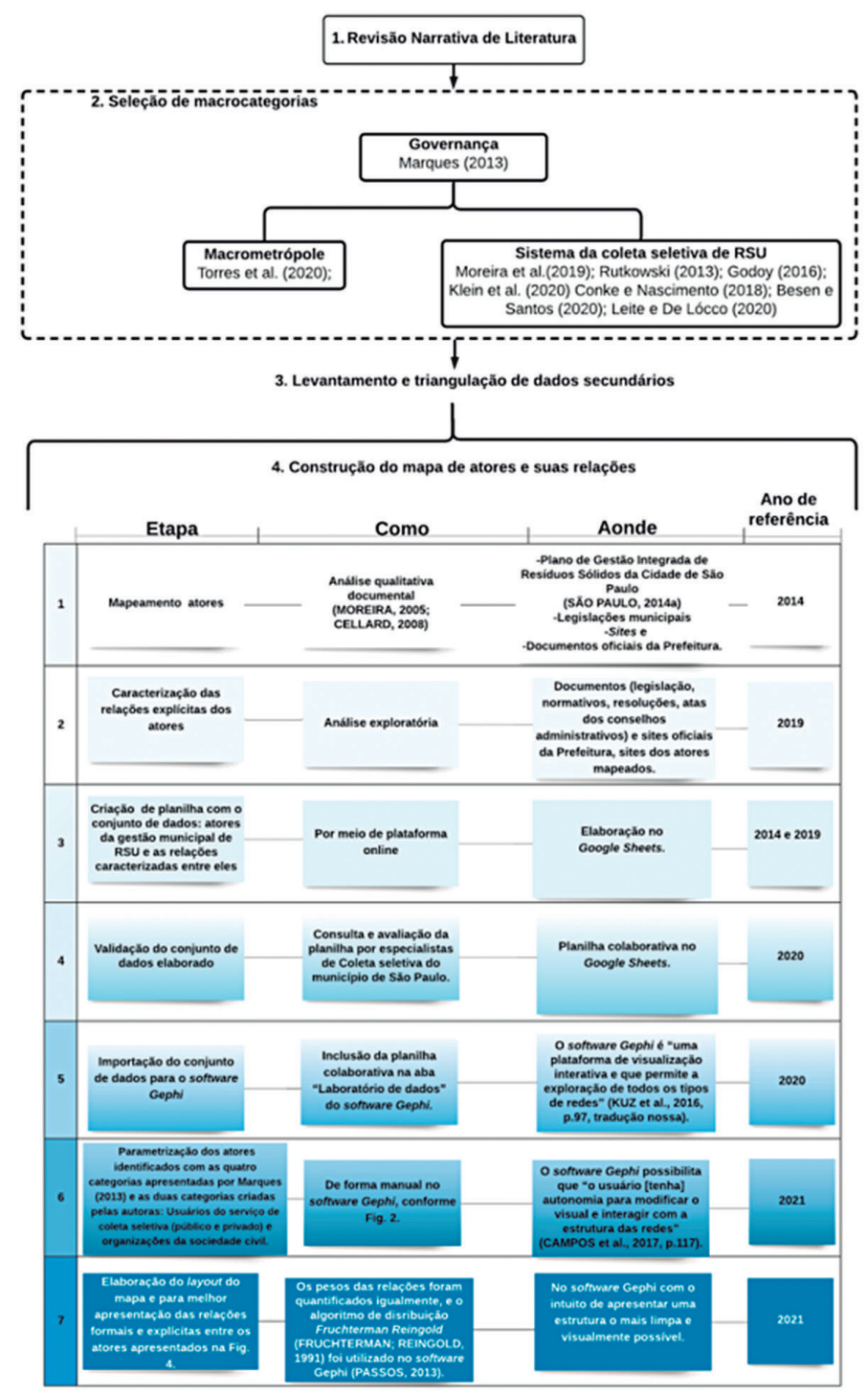

Fonte: Elaboração própria.

O mapa resultante deste estudo exibe os principais atores e as relações explícitas entre eles, tendo como foco a coleta seletiva e os dados referentes ao ano de 2019. É importante ressaltar que o mapa construído não distingue a força das relaçóes e as capacidades de influência dos diversos atores, pois para 
isso seria necessário complementar a técnica de levantamento de dados com entrevistas.

\section{Apontamentos sobre governança urbana}

Governança urbana é entendida neste artigo como os "conjuntos de atores estatais e não estatais interconectados por laços formais e informais, operando no processo de produção de políticas públicas e inseridos em configuraçôes institucionais específicas" (MARQUES, 2013, p.16-17, tradução nossa).

Os estudos urbanos e ambientais estão entre as áreas temáticas que apontam para a noção de governança como estratégia para ampliar a participação social (MARQUES, 2013). Neste contexto, a literatura recente de gestão de RSU na MMP é um importante exemplo da associação entre governança e participação (BESEN; SANTOS, 2020; FREY et al., 2020).

Besen e Santos (2020) abordam a dimensão da accountability e do controle das políticas públicas através da participação social e da corresponsabilização dos cidadãos. Os catadores de materiais recicláveis participam da gestão dos RSU, desempenhando papel central na implementação da coleta seletiva municipal. Já o Estado é responsável pelas funções de coordenar e intermediar as relações entre os atores, o que diz respeito ao elemento político, isto é, a integração de interesses e conflitos diversos.

A integração enquanto princípio para a implementação das políticas públicas envolve mecanismos de coordenação e interligaçóes entre diferentes setores governamentais, atores sociais e países (FREY et al., 2020). Nesse sentido, a governança em rede ou baseada em parcerias apresenta potencialidades, o que é ilustrado pelo caso empírico da governança de resíduos sólidos, na qual há participação de atores diversos, incluindo as cooperativas de catadores (FREY et al., 2020).

Existem pelo menos quatro padróes de governança urbana no Brasil, segundo Marques (2013, 2016): (i) grandes infraestruturas/empresas públicas; (ii) serviços urbanos; (iii) grandes projetos urbanos que envolvem exceçôes às regulaçôes urbanas; e (iv) cumprimento de regulaçóes e respeito a regras de uso e ocupação do solo urbano. Estudos de padrôes de governança podem "sugerir importantes caminhos para se entender como diferentes configuraçóes de atores, instituiçôes e redes interagem para criar diversas condiçôes de governança” (MARQUES, 2016, p. 81).

Neste contexto, Marques (2013) apresenta os principais elementos para a caracterização dos padróes de governança: (i) principais decisóes tomadas; (ii) 
processos de tomada de decisão; (iii) grau de insulamento da burocracia estatal; (iv) atores relevantes; (v) relaçóes entre atores; (vi) papel do Legislativo; e (vii) relevância do espaço urbano. Este artigo lança luz sobre o subsistema dos atores na coleta seletiva e suas relaçóes, considerando dois dos elementos dos padróes de governança dos serviços urbanos revelados por Marques (2013). Este é um primeiro esforço exploratório em uma agenda de pesquisa mais ampla para o entendimento dos padróes de governança de resíduos na MMP.

A discussão teórico-conceitual proposta por Marques (2013) avança no sentido de compreender os principais atores envolvidos nas políticas urbanas, as características institucionais (dentre elas, o federalismo) e os legados de cada política pública. Os principais atores são "burocracias e agências estatais nos diferentes níveis de governo; políticos e partidos políticos empresas privadas que obtêm seus processos de valorização a partir da produção da cidade; e movimentos sociais" (MARQUES, 2013, p.18, tradução nossa).

Quanto aos atores da sociedade civil, Marques (2013) considera os movimentos sociais, as conferências, os conselhos de políticas públicas e a atuação das organizaçóes da sociedade civil nesses espaços. Entretanto, essa é a categoria de atores menos explorada pelo autor, de modo que sáo possíveis avanços em sua caracterização que permitam captar com maior precisão a diversidade desses atores.

Assim, cabe pontuar que a categoria "movimentos sociais" foi subdividida em: (i) movimentos sociais (DIANI, 1992); (ii) usuários do serviço público (ABIKO, 2011) e privado (BRASIL, 2010); e (iii) organizaçóes da sociedade civil (LAVALLE, 2020), a fim de refletir a diversidade de atores sociais. Essa adaptação dialoga com a literatura recente, que chama a atenção para o fato de que, embora as teorias dos movimentos sociais e da sociedade civil possuam semelhanças internas, como o foco em dinâmicas societárias de contestação ou emancipação, elas "ocultam e revelam atores distintos" (LAVALLE, 2020, p. 19).

A categoria "usuários do serviço de coleta seletiva (público e privado)" emergiu da análise da própria Política Nacional de Resíduos Sólidos - PNRS (BRASIL, 2010), que destaca os consumidores como o primeiro ator envolvido no processo da coleta seletiva. Dessa maneira, o componente relacional desse serviço público e/ou privado pode ser compreendido pelas interaçóes diretas e indiretas entre usuário e prestador do serviço.

Já a categoria "organizaçóes da sociedade civil" surgiu do levantamento documental, que evidenciou a vasta participação da sociedade civil organizada em diferentes áreas da coleta seletiva da cidade de Sáo Paulo. Ainda nesta categoria, foram incluídos os acadêmicos e pesquisadores, institutos de pesquisa, 
entre outros - compreendidos por meio do conceito de comunidade epistêmica. Haas (1992, p. 3) afirma que a comunidade epistêmica diz respeito a "atores políticos que têm legitimidade para aconselhar tomadores de decisão e assumem responsabilidade delegadas, mobilizando suas crenças causais, valores, noçóes de validade de conhecimento e técnicas para a gestão pública”.

No que tange às conferências e aos conselhos, Carneiro (2002, p. 279) define que estes são "espaços públicos (não-estatais) que sinalizam a possibilidade de representação de interesses coletivos na cena política e na definição da agenda pública, apresentando um caráter híbrido, uma vez que são, ao mesmo tempo, parte do Estado e da sociedade". Os conselhos, bem como os comitês, são compostos por pessoas que representam a sociedade e/ou o governo em seus diferentes segmentos. No presente artigo, eles foram entendidos não como atores em si, mas como espaços de participação, em linha com a literatura (CARNEIRO, 2002; LAVALLE; VOIGT; SERAFIM, 2016). Portanto, a governança materializa-se no território municipal com uma gama complexa de atores, agentes e instituiçóes, apresentados na Fig. 2.

Figura 2 - Grupos de atores da governança

\begin{tabular}{|l|l|}
\hline \multicolumn{1}{|c|}{ Grupos de Atores } & \multicolumn{1}{c|}{ Descriçáo } \\
\hline $\begin{array}{l}\text { Burocracias e agências } \\
\text { estatais no nível muni- } \\
\text { cipal }\end{array}$ & $\begin{array}{l}\text { Governos locais - estados e municípios - são responsáveis pela provi- } \\
\text { são de serviço e pela implementação de políticas públicas, de acordo } \\
\text { com os legados institucionais de cada política setorial (MARQUES, } \\
\text { 2013). }\end{array}$ \\
\hline $\begin{array}{l}\text { Empresas privadas que } \\
\text { obtêm seus processos } \\
\text { de valorização a partir } \\
\text { da produção da cidade }\end{array}$ & $\begin{array}{l}\text { São os "atores de elite" (elite actors), que obtêm seus rendimen- } \\
\text { tos (processos de valorizaçáo) a partir de suas relaçóes com o esta- } \\
\text { do e dopapel do solo urbano em seus processos de valorização" } \\
\text { provedores de serviço de manutenção da cidade, como coleta de } \\
\text { RSU. }\end{array}$ \\
\hline Movimentos sociais & $\begin{array}{l}\text { Os elementos distintivos dos movimentos sociais são (i) A presença } \\
\text { de interaçóes informais entre aqueles que compóem o movimento, } \\
\text { destacando-se a pluralidade desses atores; (ii) a presença de uma } \\
\text { identidade coletiva compartilhada que pode ser considerada como } \\
\text { os sentimentos de pertencimento e de solidariedade e que vão defi- } \\
\text { nir as fronteiras do movimento; (iii) a presença de conflitos políticos } \\
\text { e/ou culturais, associados a um processo de mudança social, que } \\
\text { pode ou não se dar em um nível sistêmico (DIANI, 1992, p.13). }\end{array}$ \\
\hline
\end{tabular}




\begin{tabular}{|l|l|}
\hline \multicolumn{1}{|c|}{ Grupos de Atores } & \multicolumn{1}{c|}{ Descrição } \\
\hline $\begin{array}{l}\text { Usuário do serviço de } \\
\text { coleta seletiva (público } \\
\text { e privado) }\end{array}$ & $\begin{array}{l}\text { A opçáo pelo termo "usuários" decorre do entendimento de que, } \\
\text { sob a ótica do interesse coletivo, os consumidores são usuários dos } \\
\text { serviços (ABIKO, 2011) e pela própria PNRS (12.305/2010), que } \\
\text { destaca os consumidores como o primeiro ator envolvido no pro- } \\
\text { cesso da coleta seletiva. }\end{array}$ \\
\hline $\begin{array}{l}\text { Organizaçóes da socie- } \\
\text { dade civil }\end{array}$ & $\begin{array}{l}\text { Trata-se de "formas em maior ou menor medida estáveis de coope- } \\
\text { raçáa, coordenação e formação de sentido presentes no 'tecido socie- } \\
\text { tário' [...] [cuja racionalidade é] a resoluçáo de problemas, satisfaçáo } \\
\text { de demandas e realização de valores definidos nesses contextos." } \\
\text { (LAVALLE, 2020, p.22). }\end{array}$ \\
\hline
\end{tabular}

Fonte: Elaboração própria.

O presente artigo parte do conceito de governança definido por Marques (2013), bem como das categorias de atores estabelecidas por ele, ampliando-as, conforme a Fig. 2, para então compreender a coleta seletiva de RSU no município de São Paulo. Nesse sentido, alinha-se à literatura recente sobre este objeto empírico, que destaca a importância da participação social dos catadores nos processos de governança (BESEN; SANTOS, 2020; FREY et al., 2020).

\section{- Aspectos da coleta seletiva no município de São Paulo e o contexto da Macrometrópole Paulista}

Em 2014, a Empresa Paulista de Planejamento Metropolitano (EMPLASA) $^{7}$ delimitou a MMP, que compreende as regióes metropolitanas de São Paulo, Campinas, Baixada Santista, Sorocaba e Vale do Paraíba/Litoral Norte; as aglomeraçóes urbanas de Jundiaí e Piracicaba e a microrregião de Bragantina (PASTERNAK; BOGUS, 2019). A MMP (Fig. 3) engloba 174 municípios, o que corresponde a $50 \%$ da área urbanizada paulista (BESEN; SANTOS, 2020); (ver Tabela 1).

\footnotetext{
7 A EMPLASA foi criada pela Lei nº 94/1974 com o objetivo da realização de serviços necessários ao planejamento, programação, coordenação e controle da execução dos serviços comuns de interesse metropolitano. Apesar do reconhecimento, contudo, foi extinta pela Lei nº 17.056/2019.
} 
Figura 3 - MMP e o município de Sáo Paulo

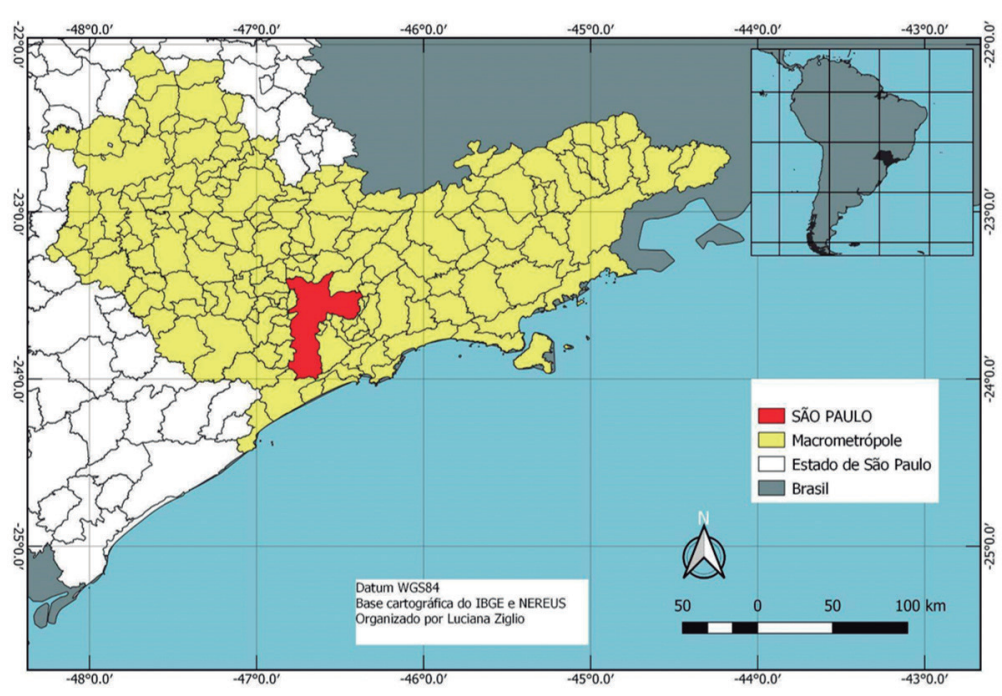

Fonte: EMPLASA (2012, p. 36). ${ }^{8}$

Torres, Ramos e Pollachi (2020, p. 104) ressaltam que "na última década, o governo do Estado de São Paulo propôs a delimitação da MMP como nova escala de planejamento e governança” (ZIONI et al., 2019; NEGREIROS; SANTOS; MIRANDA, 2015; EMPLASA, 2011; ASQUINO, 2010). Desde então, surgiram iniciativas de planejamento integrado, como o Plano de Ação da Macrometrópole (PAM) 2013-2040, para orientar o desenvolvimento desta no longo prazo e fornecer apoio ao desenvolvimento de políticas públicas (TRAVASSOS et al., 2020; NEGREIROS; SANTOS; MIRANDA, 2015), e como os Planos de Desenvolvimento Urbano Integrado (PDUIs), que, baseados no Estatuto da Metrópole (Lei Federal no 13.089/2015), são instrumentos de planejamento para regióes metropolitanas e aglomeraçóes urbanas.

$\mathrm{O}$ entendimento da escala macrometropolitana permite o planejamento e enfrentamento das questóes socioambientais (ARAÚJO et al., 2020). Entretanto, a não articulação na resolução dos problemas da MMP pode aumentar assimetrias que já existem, em especial porque os problemas socioambientais urbanos estão conectados e ocorrem "independente dos limites administrativos municipais” (ARAÚJO et al., 2020, p.105). Essa nova escala

\footnotetext{
8 A construção do mapa temático no presente no artigo foram selecionados como revisão de literatura cartográfica teórica e técnica Fitz (2008), Martinelli (2010), Menezes e Fernandes (2013) associada à geotecnologia QGis Desktop Hannover versão 3.16.3 Hannover datada de 15.01.2021".
} 
de planejamento trouxe um novo papel para a MMP e deveria aproximar os planos municipais e metropolitanos (TAVARES, 2020). Desse modo, evidencia-se a importância de pesquisas sobre macrometrópoles, assim como se ressalta a necessidade do olhar analítico para os municípios contidos nesses espaços geográficos.

É na MMP que se localiza o município de São Paulo, objeto deste artigo, caracterizado por altas taxas de urbanização, industrialização, produção e, simultaneamente, geração de resíduos (Tabela 1). A Tabela 1 a seguir sistematiza os dados de geração de RSU em uma comparação multiescalar de São Paulo. Assim, é importante que a gestão desses resíduos na MMP seja viabilizada por meio de "uma governança que efetive a participação de diversos atores, governamentais e não governamentais” (BESEN; SANTOS, 2020, p. 204).

Tabela 1 - Comparação multiescalar de São Paulo

\begin{tabular}{|c|c|c|r|r|r|c|}
\hline & \multicolumn{1}{|c|}{$\begin{array}{c}\text { Área } \\
(\mathbf{a})\end{array}$} & $\begin{array}{c}\text { Populaçáo } \\
\text { (b) }\end{array}$ & $\begin{array}{c}\text { Densidade } \\
\text { demográfica } \\
\text { (c) }\end{array}$ & $\begin{array}{c}\text { Taxa } \\
\text { Geométrica de } \\
\text { Crescimento } \\
\text { Anual (d) }\end{array}$ & $\begin{array}{c}\text { Produto Interno } \\
\text { Bruto (PIB) } \\
\text { (e) }\end{array}$ & $\begin{array}{c}\text { Geraçáo } \\
\text { de RSU } \\
\text { (f) }\end{array}$ \\
\hline $\begin{array}{c}\text { Estado de } \\
\text { Sáo Paulo }\end{array}$ & $248.219,94^{1}$ & 44.314 .9309 & 178,539 & 0,789 & $2.210 .561 .949 .480,00^{2}$ & $40.700^{7}$ \\
\hline $\begin{array}{c}\text { Macrometrópole } \\
\text { Paulista }\end{array}$ & $53.368,3161$ & $32.924 .830^{4}$ & $616,94^{4}$ & $1,02^{4}$ & $1.669 .448 .647,00^{10}$ & $30.000^{3}$ \\
\hline $\begin{array}{c}\text { Regiáo } \\
\text { Metropolitana } \\
\text { de Sáo Paulo }\end{array}$ & $7.946,98^{1}$ & 20.996 .7479 & $2.642,19$ & 0,719 & $1.280 .000 .000 .000,00^{6}$ & 20.5937 \\
\hline $\begin{array}{c}\text { Cidade de São } \\
\text { Paulo }\end{array}$ & $1.521,11^{1}$ & 11.811 .5169 & $7.765,069$ & 0,539 & $714.683 .362 .460,00^{5}$ & 12.0427 \\
\hline
\end{tabular}

(a) $\mathrm{km}^{2}$ (b)hab. (c)hab. $/ \mathrm{km}^{2}$ (d)(TGCA)2010/2021 (\% a.a.) (e)em reais (f)ton./dia.

1 Fonte: IBGE (2019a).

2 Fonte: IBGE (2018b).

3 Dados aproximados. Fonte: Besen e Santos (2020).

${ }^{4}$ Fonte: IBGE (2019c); IGC (2019).

5 Fonte: IBGE (2018a).

${ }^{6}$ Fonte: IBGE (2019b).

${ }^{7}$ Fonte: CETESB (2019).

${ }^{8}$ Fonte: EMPLASA (2016).

${ }^{9}$ Fonte: SEADE (2019).

O crescimento da população humana e a sua concentração nas cidades estão entre os fatores de configuração dos atuais padróes de produção e consumo, que possuem uma associação direta com a geração de RSU (BESEN; SANTOS, 
2020). Entretanto, deve-se considerar também na configuração desses padróes de consumo os fatores econômicos, que direcionam "ao principal objetivo de conformar um espaço de competitividade global na macrometrópole” (TAVARES, 2020, p. 1).

De fato, a MMP exige relaçóes de governança dos limites territoriais entre os municípios, mas também entre os atores que estão presentes, em maior ou menor grau, na dinâmica da produção da cidade. Assim como as delimitaçóes administrativas não são barreiras para a conectividade dos problemas, elas também não limitam a atuação desses atores. Ressalta-se ainda que "mecanismos eficazes de governança metropolitana podem [...] diminuir disparidades na provisão dos serviços públicos" (CAMPAGNONE; LEITE, 2020, p. 4). Nesse cenário, surge um problema desafiador que está associado à geração e destinação dos RSU.

A gestão e o gerenciamento de RSU são serviços públicos essenciais, de competência das municipalidades (Tabelas 1 e 2). Na perspectiva do arcabouço legal-institucional vigente, os municípios devem prestar esses serviços e arcar por eles financeiramente, atendendo às necessidades coletivas. A PNRS estabelece a governança entre os atores, com destaque para os geradores de resíduos (que também podem ser entendidos como os usuários dos serviços de coleta), os catadores, as empresas (por exemplo, prestadoras dos serviços públicos de limpeza urbana, empresas de embalagem) e os governos em todos os níveis da federação (nacional, estadual e municipal).

A legislação vigente no município (SÃO PAULO, 2002, 2020) diferencia dois regimes de prestação de serviços de limpeza urbana: no regime público, a provisão é de responsabilidade do Estado e abrange todo o território, atendendo aos munícipes-usuários e pequenos geradores empresariais. No regime privado, os serviços devem ser contratados e remunerados por cada estabelecimento que se enquadre na categoria de grandes geradores, isto é, que produza mais de 200 litros de RSU por dia ou qualquer quantidade de resíduos perigosos (exceto aqueles de serviços de saúde) ou que seja proprietário de animais mortos.

A coleta seletiva é definida pela PNRS como a "coleta de resíduos sólidos previamente separados de acordo com sua constituição e composição" (BRASIL, 2010), que será utilizada neste artigo. Já a Política Estadual de Resíduos Sólidos do Estado de São Paulo estabelece como coleta seletiva "o recolhimento diferenciado de resíduos sólidos, previamente selecionados nas fontes geradoras, com o intuito de encaminhá-los para reciclagem, compostagem, reuso, tratamento ou outras destinaçóes alternativas" (SÃO PAULO, 2006). O município de São Paulo está em consonância com as legislaçôes federais e estaduais citadas (SÃO PAULO, 2014a, 2017b). 
A coleta seletiva pode ser considerada como a primeira etapa do processo de recuperaçáo e reaproveitamento dos RSU. A finalidade e a efetividade de um programa de coleta seletiva é aumentar o fluxo de resíduos direcionados à cadeia da reciclagem (GONÇALVES-DIAS et al., 2020) Nesse sentido, a coleta seletiva apresenta-se como um serviço tipicamente logístico (BARTHOLOMEU; BRANCO; CAIXETA-FILHO, 2011). O serviço de coleta seletiva pode ser realizado pelos municípios ou pode ser delegado a empresas prestadoras de serviço contratadas por estes ou por empreendimentos diretamente interessados nos materiais recicláveis, como associaçôes ou cooperativas de catadores (GONÇALVES-DIAS et al., 2020).

Embora a questão dos RSU aponte desafios comuns, não há uma única solução, pois é preciso considerar a especificidade da cultura do descarte e do padrão de desenvolvimento socioeconômico. Há uma diversidade de vertentes relativas ao tema: condicionantes legais, inovação tecnológica, reaproveitamento, tratamento dos resíduos, geração de energia, mudanças de comportamento, estratégias de logística reversa, entre outras (GONÇALVES-DIAS, 2012). Todas elas estão interconectadas e requerem abordagens inovadoras e metodologias interdisciplinares, mas é premente estudar, debater e envolver amplamente a sociedade em torno deste tema.

Aproximando o olhar para a cidade de São Paulo, nota-se que das 5.629.076 toneladas de RSU coletadas ${ }^{9}$ em 2019, segundo dados da Prefeitura Municipal de São Paulo (SÃO PAULO, 2019), 65,38\% correspondem à coleta domiciliar e apenas $1,43 \%$ correspondem à coleta seletiva (Tabela 2).

Tabela 2 - Resíduos coletados na cidade de São Paulo (2019)

\begin{tabular}{|c|r|r|}
\hline Tipo de Resíduo & Quantidade (em toneladas) & (\%) do total coletado \\
\hline Domiciliar & $\mathbf{3 . 6 8 0 . 0 8 0}$ & $\mathbf{6 5 , 3 8 \%}$ \\
\hline Resíduos de ecoponto & 447.735 & $7,95 \%$ \\
\hline Diversos & 255.416 & $4,54 \%$ \\
\hline Entulho mecanizado & 234.540 & $4,17 \%$ \\
\hline Resíduos de córregos & 218.354 & $3,88 \%$ \\
\hline Esgoto & 200.986 & $3,57 \%$ \\
\hline Resíduos de piscináo & 189.367 & $3,36 \%$ \\
\hline
\end{tabular}

\footnotetext{
9 É de conhecimento das autoras que o total da geração de resíduos não é necessariamente correspondente ao total de resíduos coletados. Porém, uma vez que o objetivo do artigo é enfatizar os atores, os dados de geração e coleta de resíduos são tratados como equivalentes e têm função de ilustrar as dimensões da coleta regular de RSU e da coleta seletiva.
} 
Governança na coleta seletiva de resíduos sólidos urbanos: mapeamento dos atores presentes no município de São Paulo

\begin{tabular}{|c|r|r|}
\hline Tipo de Resíduo & Quantidade (em toneladas) & (\%) do total coletado \\
\hline Varrição & 81.862 & $1,45 \%$ \\
\hline Seletiva & $\mathbf{8 0 . 4 5 4}$ & $\mathbf{1 , 4 3 \%}$ \\
\hline Feira Livre & 65.326 & $1,16 \%$ \\
\hline Poda & 49.770 & $0,88 \%$ \\
\hline Entulho manual & 37.964 & $0,67 \%$ \\
\hline Grande gerador - saúde & 33.517 & $0,60 \%$ \\
\hline Resíduos de boca de lobo & 17.807 & $0,32 \%$ \\
\hline Outros & 35.896 & $0,64 \%$ \\
\hline Total & $\mathbf{5 . 6 2 9 . 0 7 4}$ & $\mathbf{1 0 0 , 0 0 \%}$ \\
\hline
\end{tabular}

Fonte: Prefeitura Municipal de São Paulo (SÃO PAULO, 2019).

Em síntese, considera-se importante o mapeamento dos atores que compóem a governança de coleta seletiva em Sáo Paulo, a fim de contribuir para a compreensão da temática gestão de resíduos sólidos na MMP, uma vez que impasses quanto à gestão podem ser comuns a diferentes cidades presentes nessa região, bem como aos atores que as integram.

\section{- Discussões e resultados}

O mapeamento revelou 37 (trinta e sete) atores com relaçóes diretas e indiretas direcionais entre si (Fig.4) e mostra a complexidade da governança da coleta seletiva no município de São Paulo, que envolve a prestação de um serviço que entrelaçam regimes contratuais públicos e privados. A seguir, apresentam-se o Mapa de Atores, os grupos de atores, segundo Marques (2013) e contribuiçóes das autoras, bem como as relaçóes de governança na coleta seletiva no município de São Paulo. 
Figura 4 - Atores e relaçóes de governança na coleta seletiva no município de São Paulo

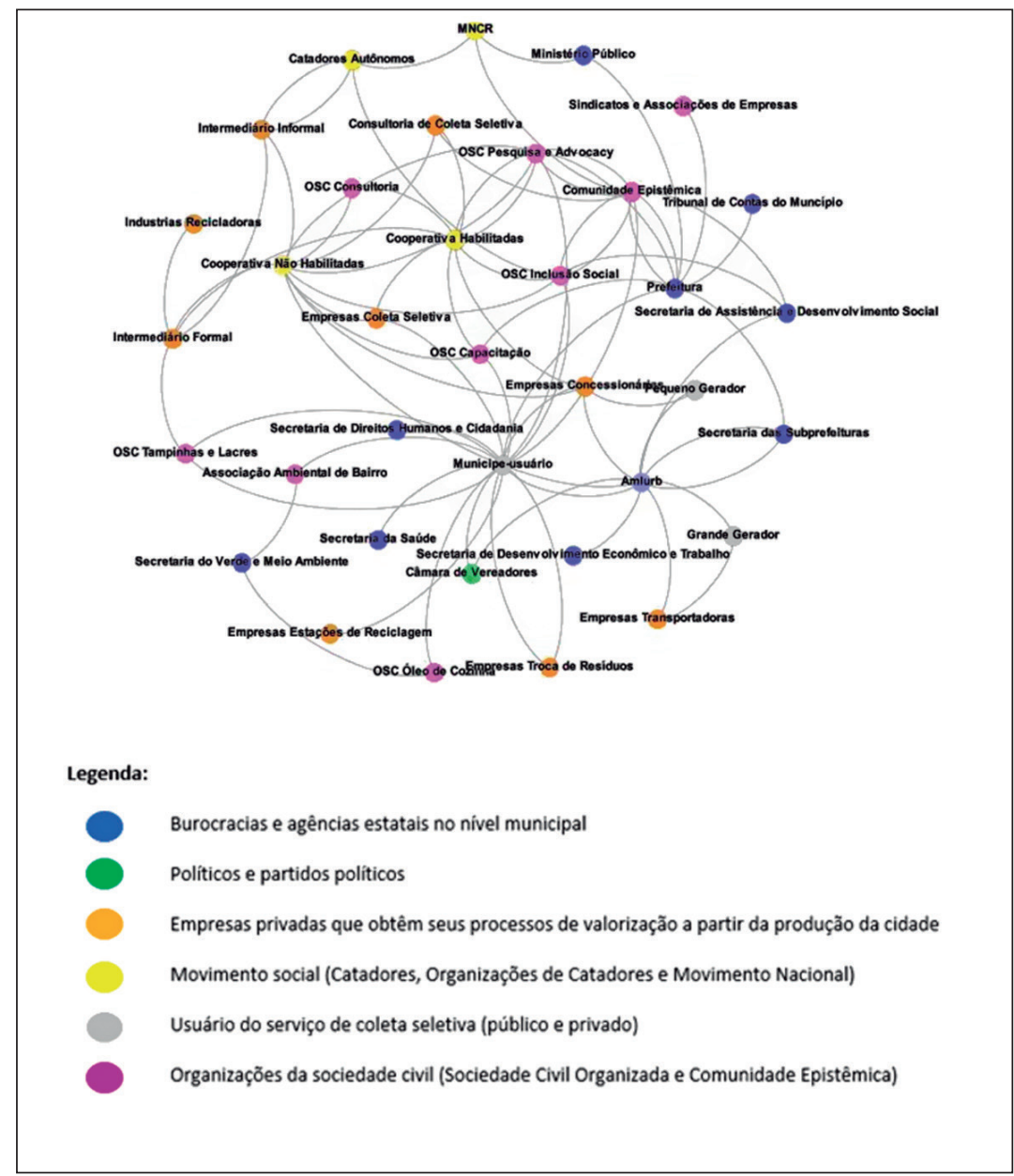

Fonte: Elaboração própria.

As próximas seções apresentam com maior detalhe os atores exibidos no mapa, a partir das categorias teóricas de atores das políticas urbanas e suas relaçôes. 


\section{O Burocracias e agências estatais no nível municipal}

Os atores estatais da coleta seletiva de São Paulo são a Prefeitura Municipal de São Paulo (PMSP), suas diversas secretarias e a Autoridade Municipal de Limpeza Urbana (AMLURB). O Tribunal de Contas do Município também é um ator estatal a ser considerado para a limpeza urbana no município de São Paulo (LACERDA, 2020) e, portanto, para a coleta seletiva.

A PMSP é responsável pela implementação das ações do Plano de Gestão Integrada de Resíduos Sólidos (PGIRS), que devem ser reproduzidas em cada subprefeitura e nos planos de bairros, conforme o Plano Diretor Estratégico da Cidade (SÃO PAULO, 2014b), e que devem ser conduzidas pelos Conselhos Regionais de Meio Ambiente, Desenvolvimento Sustentável e Cultura de Paz (CADES Regionais) e pelo Conselho Participativo Municipal (SÃO PAULO, 2014a). Existem ainda diversos programas ligados direta ou indiretamente à gestão de RSU nas secretarias municipais, das quais se destacam a Secretaria Municipal do Verde Meio Ambiente (SVMA), a Secretaria Municipal das Subprefeituras (SMSUB), a Secretaria do Desenvolvimento Econômico e Trabalho (SMDET) e a Secretaria Municipal da Saúde (SMS).

O órgão da administração pública indireta responsável pela gestão dos resíduos sólidos urbanos e limpeza urbana no município de São Paulo é a AMLURB, instituída pela Lei Municipal no 13.478/2002 (SÃO PAULO, 2002). Esse órgão deve não apenas planejar, financiar, regulamentar, fiscalizar e conduzir a política de RSU, mas também estabelecer articulaçôes com a sociedade e desenvolver ações de inclusão socioeconômica dos catadores (SÃO PAULO, 2014a, 2020). Em 2019, existiam 25 organizaçóes de catadores habilitadas por meio de um termo de colaboração pela AMLURB (SÃO PAULO, 2018) e estima-se que existam mais de 30 organizaçóes que não possuem esse vínculo formal (GONÇALVES-DIAS et al., 2020). Além disso, a AMLURB possui registros de pequenos geradores, grandes geradores, organizaçóes de catadores e empresas transportadoras em um sistema eletrônico de controle de transporte de resíduos, o CTR-e ${ }^{10}$. Esses dados auxiliam no acompanhamento e fiscalização da dinâmica dos resíduos privados e servem como subsídios para criação de políticas públicas (SÃO PAULO, 2020).

Os resultados encontrados indicam que a AMLURB está em posição centralizada no mapa enquanto os demais integrantes - burocracias e agências - encontram-se dispostos nas extremidades do mapa, estabelecendo poucas

${ }^{10}$ Disponível em: https://www.ctre.com.br/login. Acesso em: 09 mar. 2021. 
relaçóes entre outros autores, apesar de aparecerem de modo significativo na análise documental. Alinhando-se, assim, com o padrão dos serviços urbanos de Marques (2013).

\section{Políticos e partidos políticos}

A reconstrução histórica do legado institucional da política de coleta seletiva no município de São Paulo permite identificar a atuação de políticos e partidos políticos ao longo da construção da governança da coleta seletiva, seja através da análise do Executivo - os prefeitos, seus partidos e programas políticos -, seja através do debate político interno ao Legislativo e da interação entre este e o Executivo. No entanto, trata-se de um esforço analítico que, ainda que imprescindível à agenda de pesquisa que se propóe aqui, foge do escopo do presente artigo. No mapa de atores apresentado (Fig. 4), a categoria de políticos e partidos políticos de Marques (2013) é representada de maneira mais ampla pela Câmara de Vereadores do município.

\section{- Empresas privadas que obtém seus processos de valorização a partir da produção da cidade}

Os atores empresariais da coleta seletiva de São Paulo são as empresas concessionárias de coleta e varrição, as empresas transportadoras de resíduos, as empresas privadas de coleta seletiva, de estaçóes de reciclagem e de pontos de troca de resíduos, as consultorias especializadas e os intermediários comerciais formais e informais entre a coleta seletiva e a indústria recicladora.

As empresas concessionárias da coleta domiciliar de RSU e de varrição de vias são um tipo de "capital do urbano" (MARQUES, 2013). Essas empresas e suas relaçóes com o Estado já foram abordadas pela literatura (GODOY, 2016; GAMBI, 2018). Na cidade de São Paulo, a prestação do serviço divisível de coleta seletiva é realizada por dois consórcios: Logística Ambiental de São Paulo S.A. (Loga), responsável pelo agrupamento territorial noroeste, e EcoUrbis Ambiental S. A., responsável pelo agrupamento territorial sudeste (GODOY, 2016).

As concessionárias destinam os resíduos sólidos por elas coletados, prioritariamente, para as duas Centrais Mecanizadas de Triagem (CMTs) e para as cooperativas habilitadas pela AMLURB e, mesmo que de maneira descontínua (GONÇALVES-DIAS et al., 2020), destinam o excedente às cooperativas não habilitadas do município (SÃO PAULO, 2014a). Embora os investimentos para a construção das CMTs tenham sido realizados pelas concessionárias 
Loga e EcoUrbis ${ }^{11}$, a propriedade dessas CMTs é da municipalidade. Já a operação das CMTs é compartilhada entre as concessionárias Loga, EcoUrbis e duas cooperativas habilitadas pela AMLURB, denominadas gerenciadoras, que, entretanto, estão submetidas ao Conselho de Acompanhamento do Programa Socioambiental (SÃO PAULO, 2017a).

Uma vez que Loga e EcoUrbis são agentes executores de natureza privada e externa à administração pública, torna-se necessário o estabelecimento de vínculos formais entre esta e esses agentes (GAMBI, 2018). No caso de São Paulo, esse vínculo é o contrato de concessão (GODOY, 2016; GAMBI, 2018). Os contratos de concessão atuais com os consórcios Loga e EcoUrbis foram firmados em 2004 e têm prazo de 20 anos (passíveis de prorrogação). Os mecanismos atuais de gestão, controle e fiscalização dos serviços executados pelas concessionárias são implementados pela AMLURB (GONÇALVES-DIAS et al., 2020). Esses vínculos caracterizam os arranjos institucionais de implementação da coleta seletiva e refletem, de maneira geral, as relaçóes entre os atores estatais e não estatais presentes nos diversos territórios (GAMBI, 2018).

É importante notar que nem todas as empresas privadas prestadoras de serviços relacionados à coleta de RSU têm seus clientes apenas no Estado. Este é o caso das empresas transportadoras: embora suas atividades sejam regulamentadas pelo Estado - no caso de São Paulo, pela AMLURB, através do CTR-e anteriormente mencionado - essas empresas prestam serviços de coleta diretamente aos grandes geradores. Esse é também o caso das empresas privadas de coleta seletiva (Fig. 4), que, de maneira geral, não têm sua atuação regulamentada pela Prefeitura/AMLURB; ainda assim, algumas dessas empresas possuem uma relação pontual com a Prefeitura.

Existem ainda empresas privadas que possuem pontos de entrega voluntária de resíduos e empresas privadas que trocam resíduos sólidos por pontos que, por sua vez, podem ser trocados por bens e serviços (Fig. 4). Essas empresas estão em contato direto com os munícipes. É interessante notar que essas empresas obtêm seus rendimentos a partir dos resíduos gerados pelo funcionamento da cidade.

O mapa de atores identificou também a existência de consultorias especializadas em coleta seletiva (Fig. 4), cuja atuação incide sobre a governança desta, à medida que promovem práticas sustentáveis e valorizam atores. Nesse sentido, é interessante apontar que, em sua grande maioria, essas consultorias reconhecem a importância das cooperativas de catadores.

11 Disponível em: https://www.prefeitura.sp.gov.br/cidade/secretarias/inovacao/noticias/?p=174208. Acesso em: 09 mar. 2021. 
Deve-se considerar, enfim, os intermediários formais e informais e a indústria recicladora como atores que também se inserem na lógica de mercado e de valorização que decorre do funcionamento da coleta seletiva na cidade. Os intermediários (também conhecidos como sucateiros, depósitos, ferros-velhos) obtêm seus rendimentos pela mediação comercial entre a atividade de coleta seletiva realizada por organizaçóes de catadores e catadores autônomos e a atividade industrial. Existem 550 intermediários formalizados, e estima-se que 5.000 intermediários operem de maneira informal em relação às licenças e autorizações para o desempenho de suas atividades (SÃO PAULO, 2014a). Já a indústria recicladora está no limite desse processo: sua matéria-prima provém dos resíduos gerados pelo funcionamento da cidade, isto é, provém da coleta seletiva.

Assim, a grande maioria dos atores empresariais tem relação com os geradores de resíduos - sejam estes os munícipes-usuários, os pequenos ou os grandes geradores. As empresas concessionárias possuem relaçôes formais com os munícipes-usuários, pequenos geradores, AMLURB/CMTs e cooperativas de catadores, principalmente as habilitadas; já as empresas transportadoras possuem relaçóes formais com os grandes geradores e com a AMLURB. As empresas privadas de coleta seletiva, de pontos de entrega voluntária e de pontos de troca de resíduos possuem relaçôes principalmente com os munícipes-usuários e estão mais distantes dos atores estatais no mapa; estas relaçóes não necessariamente passam pela estruturação formal e normativa da política. Por fim, os intermediários comerciais formais e informais e a indústria recicladora estão na margem do mapa de atores, possuindo vínculos formais e informais com os catadores e algumas organizaçôes da sociedade civil.

\section{- Atores da sociedade civil}

Os atores sociais da coleta seletiva de São Paulo são os usuários do serviço de coleta seletiva público e privado, o movimento social que representa os catadores de materiais recicláveis, os diversos tipos de organizaçóes da sociedade civil (OSCs) e a comunidade epistêmica (acadêmicos e pesquisadores) relacionada à gestão de resíduos sólidos com inclusão de catadores. Esses diversos atores serão detalhados a seguir.

\section{Usuários do serviço de coleta seletiva (público e privado)}

Os usuários do serviço de coleta seletiva público e privado no município de São Paulo abarcam os munícipes-usuários, os pequenos geradores e os grandes 
geradores. Os munícipes-usuários e os pequenos geradores são compreendidos como "pessoas físicas ou jurídicas inscritas no Cadastro Imobiliário Fiscal do Município”, cuja geração de RSU é inferior ao volume de 200 litros diários (SÃO PAULO, 2002). Esses usuários têm as responsabilidades de acondicionar adequadamente os RSU gerados e disponibilizá-los para a coleta do sistema municipal (BRASIL, 2010).

Os grandes geradores são os proprietários ou titulares de estabelecimentos públicos, institucionais, de prestação de serviços, comerciais e industriais, bem como os condomínios de edifícios náo residenciais ou de uso misto, cuja geração de resíduos sólidos é superior ao volume de 200 litros diários. Os grandes geradores devem contratar empresas privadas de coleta, transporte, tratamento e destinação final de resíduos (SÃO PAULO, 2002), isto é, as empresas transportadoras descritas anteriormente.

Assim, a partir do mapa de atores (Fig. 4), é possível observar quem mantém centralidade na governança da coleta seletiva no município de São Paulo: os munícipes-usuários se encontram em uma posição mais central no mapa de atores da coleta seletiva, apresentando diversas relaçóes formais e informais: com atores estatais, empresariais e demais atores sociais; entretanto, pequenos e grandes geradores se encontram mais à margem do mapa, apresentando poucas relaçóes formais e normativas: com AMLURB, empresas concessionárias e transportadoras.

\section{Movimento social: catadores autônomos, organizações de catadores e MNCR}

O movimento social envolvido com o(a) catador(a) de materiais recicláveis é composto pelos seguintes atores: o Movimento Nacional dos Catadores de Materiais Recicláveis (MNCR, 2019), cujo objetivo é organizar "catadores e catadoras de materiais recicláveis pelo Brasil [...] estejam eles em lixóes a céu aberto, nas ruas ou em processo de organização" ${ }^{12}$; as cooperativas de catadores(as) habilitadas e não habilitadas; e os(as) catadores(as) autônomos(as).

As organizaçóes de catadores são um importante elo entre poder público, população e setor privado para a consolidação da gestão integrada de RSU. O reconhecimento do catador como um dos atores na gestáo e no gerenciamento dos RSU, explicitamente expresso pela PNRS, foi uma consequência de longos anos de mobilização dessa categoria de trabalhadores (WIRTH; OLIVEIRA,

12 Movimento Nacional dos Catadores de Materiais Recicláveis. MNCR. 07.06.2018. "O que é o Movimento?" Disponível em: https://www.mncr.org.br/sobre-o-mncr/o-que-e-o-movimento. Acesso em: 24 mar. 2021. 
2016). Teodósio, Gonçalves-Dias e Santos (2014) consideram que o Decreto no 7.404/2010 regulamentou a PNRS estabelecendo a institucionalização de parcerias municipais com as organizaçóes de catadores como um de seus pilares. A atuação dessas organizaçôes ocorre de diferentes maneiras, mais ou menos qualificadas, podendo restringir-se à triagem do material que é coletado por terceiros ou englobar também a prestação do serviço da coleta e a realização de atividades de educação ambiental (GAMBI, 2018). Não obstante, deve-se destacar que os convênios formais com as prefeituras nem sempre garantem condiçôes dignas de trabalho àqueles que atuam em organizaçôes de catadores (TEODÓSIO; GONÇALVES-DIAS; SANTOS, 2014).

$\mathrm{Na}$ prática, as experiências brasileiras de gestão compartilhada entre poder público e organizaçóes de catadores apontam para uma grande dificuldade das prefeituras em incorporar, de fato, as associaçóes e/ou cooperativas de catadores. Embora os governos municipais muitas vezes se disponham a contratar os catadores, o tratamento conferido a eles é extremamente desigual, tanto em termos de volume de recursos, quanto em termos de garantias, quando comparado ao tratamento concedido às empresas (GRIMBERG, 2005). O resultado tem sido o estabelecimento de parcerias em bases muito frágeis e com forte dependência das decisóes governamentais, que variam entre gestóes e mandatos municipais (GAMBI, 2018).

Do universo de organizações de catadores no município de São Paulo, havia, em 2019, 25 cooperativas habilitadas pela AMLURB para o Programa de Coleta Seletiva Municipal, sendo que uma delas tinha atuação específica com os resíduos de equipamentos eletroeletrônicos. De acordo com mapeamento do Movimento Nacional de Catadores de Materiais Recicláveis (MNCR, 2019), existiam 32 cooperativas não habilitadas pela Prefeitura. Somando os dois grupos, existia naquele ano um universo de aproximadamente 57 organizaçóes de catadores $^{13}$ na cidade de Sáo Paulo.

Estima-se que existam cerca 13 mil catadores autônomos na cidade de São Paulo (GONÇALVES-DIAS et al., 2020). Os catadores autônomos atuam de maneira independente nas ruas dos principais centros urbanos e não possuem vínculos formalizados com poder público, empresas ou cooperativas. Existe grande diversidade entre os perfis desses catadores, que variam em relação a rotas, horários e locais de coleta, bem como em relação à utilização ou não de veículos automotores ou carroças; destaca-se o trabalho em locais com grandes aglomeraçóes de pessoas, como eventos públicos (GONÇALVES-DIAS et al.,

\footnotetext{
13 Esse número não representa a totalidade das organizações, dado o grande número de grupos informais existentes, mas indica um número importante dos grupos de catadores formais que atuam na cidade.
} 
2020). Conforme discutido anteriormente, os intermediários mediam as relaçóes comerciais entre catadores e indústria recicladora e, em geral, operam com alto índice de informalidade, especialmente na relação trabalhista com os catadores autônomos.

As cooperativas de catadores também possuem centralidade na governança da coleta seletiva no município de São Paulo: encontram-se em uma posição mais central no mapa de atores e também apresentam diversidade de relaçóes; enquanto as cooperativas habilitadas pela AMLURB possuem uma relação com o Estado, formalizada por meio de termo de colaboração, as cooperativas não habilitadas, não possuem esta relação. Entretanto, isso não impede, a priori, as cooperativas não habilitadas de se relacionarem com os demais atores, como mostra o mapa de atores (Fig. 4). Por outro lado, os catadores autônomos estão à margem do mapa de atores e possuem poucas relaçóes, que são marcadas pela informalidade.

\section{Sociedade civil organizada e comunidade epistêmica}

Os diversos atores da sociedade civil organizada são parceiros na promoção da coleta seletiva (SÃO PAULO, 2014a). Nesse sentido, podem ser localizadas as OSCs de consultoria, de advocacy e pesquisa, de inclusão social e de capacitação (Fig. 5), bem como a academia e seus pesquisadores de diferentes disciplinas. Embora não partilhem da identidade coletiva dos(as) catadores(as), essas organizaçóes estão envolvidas no processo de construção coletiva de crenças e de solidariedades desse movimento social e adotam o mesmo posicionamento em relação ao projeto de mudança social, qual seja, a coleta seletiva com a inclusão dos(as) catadores(as). Nas análises sobre os atores da sociedade civil, o foco se dá sobre "a densidade do tecido societário e das práticas de sociabilidade e seus valores morais” (LAVALLE, 2020, p. 25). Essa ampliação do espectro de atores sociais que podem ser observados é de particular interesse para a presente análise, uma vez que permite abarcar as organizaçóes da sociedade civil que estáo para além do movimento social dos(as) catadores(as) e que podem, inclusive, ocupar uma posição oposta a esse movimento.

Assim, o mapa de atores da governança da coleta seletiva é composto também de atores da sociedade civil associados a valores mais amplos de defesa do meio ambiente e sustentabilidade, como as OSCs de coleta de óleo de cozinha e as associaçóes ambientais de bairro (Fig. 5). Embora essas associaçóes não possuam relaçóes diretas com cooperativas de catadores ou catadores autônomos, elas possuem permeabilidade no território e relaçóes com os munícipes. Ademais, 
essas associaçóes possuem cadastro na Secretaria Municipal do Verde e Meio Ambiente, de modo que apresentam potencial para o fomento à coleta seletiva, atuando como elo entre Estado, munícipes e catadores.

As OSCs que coletam tampinhas plásticas e lacres de alumínio, por sua vez, possuem relação apenas com os munícipes. Há um importante engajamento destes com essas OSCs. Assim, são características desse conjunto de atores OSCs de coleta de óleo de cozinha, associaçôes ambientais de bairro e OSCs de tampinhas e lacres - o posicionamento mais à margem do mapa, mas a importante incidência junto aos munícipes, de modo que esse conjunto de atores, imerso no tecido societário, estabelece práticas de sociabilidade, bem como forma sentidos e valores que podem ser associados à coleta seletiva e a questóes ambientais mais amplas.

Por fim, os sindicatos e as associaçóes de empresas privadas de limpeza urbana (por exemplo: Associação Brasileira de Empresas de Limpeza Pública e Resíduos Especiais - Abrelpe; Associação Brasileira de Empresas de Tratamento de Resíduos e Efluentes - ABETRE; Sindicato das Empresas de Limpeza Urbana - SELUR) são atores coletivos empresariais vinculados à limpeza urbana a partir de uma "perspectiva empresarial dos serviços de coleta seletiva” (GODOY, 2016, p.71).

As organizações da sociedade civil encontram-se dispersas pelo mapa de atores e apresentam relaçóes diversas, mas, em sua grande maioria, informais, isto é, não são estruturadas pela política pública. Por exemplo, o PGIRS (SÃO PAULO, 2014a) destaca que essas organizaçóes são importantes parceiras para a ampliação e o fortalecimento da coleta seletiva do município. As OSCs que possuem vínculo com a SVMA são a exceção, mas esse vínculo não diz respeito diretamente ao Programa Municipal de coleta seletiva. A dispersão pelo mapa e a variação nas relações pode ser atribuída aos diferentes focos de atuação dessas organizaçóes, conforme discutido acima e detalhado na Fig. 5. 
Figura 5 - Iniciativas privadas (Organizações da Sociedade Civil e Empresas) que colaboram com a Coleta Seletiva em São Paulo, 2019

\begin{tabular}{|c|c|c|}
\hline Iniciativas & Descriçáo & Exemplos \\
\hline OSC Consultoria & $\begin{array}{l}\text { Organizaçóes da sociedade civil } \\
\text { que oferecem apoio e suporte no } \\
\text { âmbito da Coleta Seletiva muni- } \\
\text { cipal para prefeituras, empresas e } \\
\text { condomínios. }\end{array}$ & $\begin{array}{l}\text { Instituto de Projetos e Pesqui- } \\
\text { sa Socioambientais - IPESA; } \\
\text { Recicleiros; Instituto Lixo Zero } \\
\text { (ZWIA - Zero Waste Internatio- } \\
\text { nal Alliance) }\end{array}$ \\
\hline $\begin{array}{l}\text { OSC Pesquisa e } \\
\text { Advocacy }\end{array}$ & $\begin{array}{l}\text { Organizaçóes da sociedade civil } \\
\text { que realizam pesquisas sobre } \\
\text { resíduos sólidos e seus impactos } \\
\text { ambientais, econômicos e sociais. }\end{array}$ & $\begin{array}{l}\text { Rede Nossa Sáo Paulo; Instituto } \\
\text { Pólis - Estudos Formaçáo e Asses- } \\
\text { soria em Políticas Sociais; Insti- } \\
\text { tuto de Biologia Marinha e Meio } \\
\text { Ambiente - IBIMM. }\end{array}$ \\
\hline OSC Capacitação & $\begin{array}{l}\text { Organizaçôes da sociedade civil, } \\
\text { estruturadas nos pilares da susten- } \\
\text { tabilidade e educação ambiental } \\
\text { que oferecem cursos de formaçáo } \\
\text { e capacitaçáo para cooperativas e } \\
\text { catadores. }\end{array}$ & $\begin{array}{l}\text { ONG } 341 \text { Caminho Suave; Insti- } \\
\text { tuto Ecoar para a Cidadania; Ins- } \\
\text { tituto GEA. }\end{array}$ \\
\hline $\begin{array}{l}\text { OSC Inclusão } \\
\text { Social }\end{array}$ & $\begin{array}{l}\text { Organizaçôes da sociedade civil } \\
\text { que promovem, através da coleta } \\
\text { de materiais recicláveis, a inclusão } \\
\text { social de pessoas em situaçấo de } \\
\text { vulnerabilidade. }\end{array}$ & $\begin{array}{l}\text { Associação Reciclázaro; Serviço } \\
\text { Franciscano de Apoio a Recicla- } \\
\text { gem (Recifran); Centro Gaspar } \\
\text { Garcia de Direitos Humanos (Pro- } \\
\text { grama Reviravolta). }\end{array}$ \\
\hline $\begin{array}{l}\text { Associaçáo } \\
\text { Ambiental de } \\
\text { Bairro }\end{array}$ & $\begin{array}{l}\text { Associaçóes de bairro cadastradas } \\
\text { na SVMA, que desenvolvem açóes } \\
\text { ambientais, e poderiam se tornar } \\
\text { pontos irradiadores de boas práti- } \\
\text { cas para a Coleta Seletiva. }\end{array}$ & $\begin{array}{l}\text { Associação Aliança Libertária } \\
\text { Meio Ambiente; Instituto Saúde e } \\
\text { Sustentabilidade; SOS Manancial; } \\
\text { The Green Initiative; ICLEI Brasil. }\end{array}$ \\
\hline $\begin{array}{l}\text { OSC Óleo de } \\
\text { Cozinha }\end{array}$ & $\begin{array}{l}\text { Organizaçôes da sociedade civil } \\
\text { que atuam como pontos voluntá- } \\
\text { rios de coleta de óleo de cozinha, } \\
\text { buscam a proteção ambiental e o } \\
\text { desenvolvimento de práticas sus- } \\
\text { tentáveis. }\end{array}$ & $\begin{array}{l}\text { Associação Ministério Semente; } \\
\text { Associação Brasileira para Sen- } \\
\text { sibilização, Coleta e Reciclagem } \\
\text { de Resíduos de Óleo Comestível } \\
\text { (Ecóleo); Ong Trevo. }\end{array}$ \\
\hline $\begin{array}{l}\text { OSC Tampinhas e } \\
\text { lacres }\end{array}$ & $\begin{array}{l}\text { Organizaçóes da sociedade civil } \\
\text { que atuam como pontos entrega } \\
\text { voluntários de materiais reciclá- } \\
\text { veis, principalmente tampas plás- } \\
\text { ticas e de lacres de alumínio. }\end{array}$ & $\begin{array}{l}\text { Ecopatas; ONG Cáotinho do } \\
\text { Bem; Fazer o Bem Transforma; } \\
\text { Tampinha Legal; Associação para } \\
\text { Desenvolvimento, Educação } \\
\text { Recuperação do Excepcional } \\
\text { (ADERE). }\end{array}$ \\
\hline
\end{tabular}




\begin{tabular}{|l|l|l|}
\hline \multicolumn{1}{|c|}{ Iniciativas } & \multicolumn{1}{|c|}{ Descriçáo } & \multicolumn{1}{c|}{ Exemplos } \\
\hline $\begin{array}{l}\text { Empresas de } \\
\text { Coleta Seletiva }\end{array}$ & $\begin{array}{l}\text { Empresas privadas que oferecem } \\
\text { serviço de coleta seletiva ou logísti- } \\
\text { ca reversa (embalagens/ vidros) em } \\
\text { condomínios, empresas ou estabe- } \\
\text { lecimentos cadastrados. }\end{array}$ & $\begin{array}{l}\text { Instituto Muda; GreenMining; } \\
\text { Massfix; Trashin. }\end{array}$ \\
\hline $\begin{array}{l}\text { Empresas de troca } \\
\text { de resíduos sólidos } \\
\text { por prêmios }\end{array}$ & $\begin{array}{l}\text { Empresas privadas que atuam } \\
\text { como ponto de entrega voluntária } \\
\text { de materiais recicláveis específicos } \\
\text { e oferecem em troca produtos, ser- } \\
\text { viços ou descontos. }\end{array}$ & $\begin{array}{l}\text { So+ma Vantagens; AES Eletropau- } \\
\text { lo (Recicle mais, pague menos) } \\
\text { Enel (Econel); Triciclo (Programa } \\
\text { Triciclo); Molécoola. }\end{array}$ \\
\hline $\begin{array}{l}\text { Empresas que } \\
\text { possuem estaçóes } \\
\text { de reciclagem } \\
\text { (PEV/Ecoponto) }\end{array}$ & $\begin{array}{l}\text { Empresas privadas de outros seto- } \\
\text { res que possuem dentro de sua } \\
\text { infraestrutura pontos de entrega } \\
\text { voluntária ou ecopontos para a } \\
\text { coleta de materiais recicláveis. }\end{array}$ & $\begin{array}{l}\text { Páo de Açúcar Unilever (GPA); } \\
\text { Grupo Carrefour; Leroy Merlin. }\end{array}$ \\
\hline $\begin{array}{l}\text { Consultorias } \\
\text { especializadas em } \\
\text { coleta seletiva }\end{array}$ & $\begin{array}{l}\text { Empresas privadas que oferecem } \\
\text { serviços de consultoria e pesqui- } \\
\text { sa em temas relacionados à coleta } \\
\text { seletiva. }\end{array}$ & $\begin{array}{l}\text { I\&T Gestáo de Resíduos Sólidos; } \\
\text { PwC; New Hope Ecotech; Giral; } \\
\text { Cicla Brasil; TriCiclos; Boomera. }\end{array}$ \\
\hline
\end{tabular}

Fonte: Elaboração própria com base em Gonçalves-Dias et al. (2020). ${ }^{14}$

\section{Espaços democráticos de participação}

Os espaços democráticos de participação congregam atores de naturezas diversas e podem influenciar as políticas públicas. Entretanto, é importante notar que eles não constam no mapa de atores justamente porque não são atores em si. Assim, esta seção caracteriza brevemente os espaços identificados para o caso de São Paulo e apresenta os apontamentos da literatura recente.

O Conselho Municipal do Meio Ambiente e Desenvolvimento Sustentável, a IV Conferência Municipal de Meio Ambiente e o Comitê Intersecretarial para Política Municipal de Resíduos Sólidos foram espaços importantes de debate sobre RSU e coleta seletiva. O PGIRS do município de São Paulo foi construído nos espaços da IV Conferência e do Comitê Intersecretarial, com ampla participação social (SÃO PAULO, 2014a). Outro espaço de participação

\footnotetext{
14 Análise documental em sites das iniciativas, organizações e empresas citadas na tabela; PGIRS (SÃO PAULO, 2014a) e site do município. Disponível em: https:/www.prefeitura.sp.gov.br/cidade/secretarias/meio_ambiente/. Acesso em: 21 jan. 2022.
} 
social institucionalizada da política municipal de coleta seletiva é o Conselho de Acompanhamento do Programa Socioambiental de Coleta Seletiva de Resíduos Recicláveis, do qual participam representantes da AMLURB, de secretarias municipais, das cooperativas habilitadas e das cooperativas gerenciadoras das CMTs (SÃO PAULO, 2017a).

Os diferentes espaços de participação permitem o encontro de atores de naturezas distintas (Estado, empresas, atores sociais), com visóes distintas, onde pode ser observada a governança na prática. No entanto, conforme destacam Lavalle, Voigt e Serafim (2016), os efeitos produzidos pelos conselhos ainda são pouco conhecidos. Nesse sentido, Besen e Santos (2020) afirmam que há baixa efetividade dos espaços democráticos de participação na cidade de São Paulo e apresentam a ressalva de que "construir espaços de participação democráticos não implica, diretamente, boa governança” (BESEN; SANTOS, 2020, p.210).

No que tange à incidência sobre a política de RSU e à integração dos catadores em sua gestão, Frey et al. (2020) pontuam como desafios a existência de interesses distintos e de relaçóes econômicas e de poder desiguais em torno do serviço público da coleta seletiva, o que determina influências desiguais sobre os processos decisórios; a pouca abertura dos governos locais à integração dos catadores nos processos de tomada de decisão; o planejamento setorial - isto é, compartimentado - das administraçóes públicas; e a ausência de continuidade administrativa nas mudanças de gestão. Embora Frey et al. (2020) reconheçam a fragilidade e as assimetrias dos arranjos de governança urbana, enfatizam a relevância da construção de espaços participativos, como comitês, para a incidência dos atores sociais sobre a governança local e regional da gestão dos RSU.

Desse modo, há uma variedade de atores que integram a coleta seletiva de São Paulo, revelados pelo mapeamento aqui apresentado. Além das categorias previstas por Marques (2013), foi possível especificar mais duas categorias de atores na governança da coleta seletiva, os usuários do serviço de coleta seletiva (público e privado) e as organizaçôes da sociedade civil. Para finalizar, a próxima seção traz uma síntese dos atores mais relevantes na governança da coleta seletiva no município de São Paulo.

\section{Atores relevantes na Governança da Coleta Seletiva de São Paulo}

Foi possível destacar três atores na governança da coleta seletiva em São Paulo: as cooperativas de catadores, habilitadas e não habilitadas; os munícipes-usuários; e a AMLURB. Isso decorre da centralidade desses atores no mapa, 
da grande quantidade de relaçóes que estabelecem com os demais atores e da diversidade dessas relaçóes, que são tanto formais, quanto informais.

Figura 6 - Síntese dos Atores relevantes na

Governança da Coleta Seletiva de São Paulo

\begin{tabular}{|c|c|c|}
\hline Atores Relevantes & Relaçóes com os grupos de atores & Principal Função na Governança \\
\hline Cooperativas & $\begin{array}{l}\text { - Burocracias e Agências Estatais } \\
\text { - Companhias Privadas } \\
\text { - Usuários do Serviço } \\
\text { - Sociedade Civil Organizada } \\
\text { - Movimentos Sociais }\end{array}$ & $\begin{array}{l}\text { As organizaçóes de catadores são } \\
\text { um importante elo entre o poder } \\
\text { público e o setor privado para a } \\
\text { consolidaçáa da gestấo de coleta } \\
\text { seletiva no município de São Paulo. } \\
\text { Realizam etapas de triagem e bene- } \\
\text { ficiamento dos RSU, que viabiliza } \\
\text { a reciclagem dos materiais. }\end{array}$ \\
\hline Munícipe-usuário & $\begin{array}{l}\text { - Burocracias e Agências Estatais } \\
\text { - Companhias Privadas } \\
\text { - Políticos e Partidos } \\
\text { - Sociedade Civil Organizada } \\
\text { - Movimentos Sociais }\end{array}$ & $\begin{array}{l}\text { Primeiro ator envolvido no pro- } \\
\text { cesso de coleta seletiva, pois tem a } \\
\text { responsabilidade de separar, acon- } \\
\text { dicionar os RSU gerados e dispo- } \\
\text { nibilizá-los para a coleta do sistema } \\
\text { municipal. }\end{array}$ \\
\hline AMLURB & $\begin{array}{l}\text { - Burocracias e Agências Estatais } \\
\text { - Companhias Privadas } \\
\text { - Usuários do Serviço } \\
\text { - Políticos e Partidos } \\
\text { - Sociedade Civil Organizada } \\
\text { - Movimentos Sociais } \\
\end{array}$ & $\begin{array}{l}\text { Ator estatal responsável pela gestão } \\
\text { de resíduos sólidos urbanos e lim- } \\
\text { peza urbana no município de São } \\
\text { Paulo, que deve planejar, financiar, } \\
\text { regulamentar, fiscalizar e conduzir a } \\
\text { política de RSU no município. }\end{array}$ \\
\hline
\end{tabular}

Fonte: Elaboração própria.

O conjunto dos três atores mostrados na Fig. 6 nos faz retomar o padrão de governança dos serviços urbanos mostrado por Marques (2013), onde os atores relevantes são as burocracias estatais e os provedores do serviço público - nesta análise, representados por AMLURB e cooperativas de catadores. Entretanto, diferentemente de Marques (2013), identificou-se também a importância dos munícipes-usuários na governança da coleta seletiva, o que decorreu da análise documental dos principais instrumentos da política de gestão de resíduos sólidos do município, que enfatizam a entrega do serviço ao munícipe. A presente análise está em linha com o elemento relacional do padrão de governança dos serviços urbanos em São Paulo, uma vez que as relaçóes que constituem a governança da coleta seletiva podem ser caracteri- 
zadas como uma "rede comunitária vagamente centrada no tecido relacional do Estado” (MARQUES, 2013, p. 30).

\section{- Considerações finais}

O mapa apresentou quem são os atores e quais as relaçóes presentes na governança da coleta seletiva de São Paulo. Entretanto, é importante notar que estar presente na política e possuir relaçóes diversas não significa, necessariamente, exercer influência na governança ou ter poder de influenciar a política pública, como é o caso da sociedade civil e dos catadores em suas variadas formas de relaçóes com a AMLURB. O mapeamento é relevante para compreender a política e, com o avançar nessa agenda de pesquisa, identificar seus padróes de governança (MARQUES, 2013).

Desta forma, mapear os atores e suas relaçóes mostrou que uma abordagem integrada da governança da coleta seletiva não depende de um único agente, capaz de resolver todos os problemas e desafios. Depende, sobretudo, de uma visão sistêmica, considerando o emprego de múltiplos métodos e a colaboração entre os atores (usuários, empresas, governos, catadores, sociedade civil, entre outros), através de um modelo de gestão integrada que reconheça os papéis e interesses de cada um, bem como decisóes que considerem as condiçôes e capacidade locais.

Apesar de a gestão de resíduos sólidos ser, na grande maioria, incumbência dos municípios, os atores que compóem este campo e suas respectivas dinâmicas extrapolam os limites do território municipal e, em muitos casos, do território nacional. Considerar São Paulo como centro irradiador de governança para a MMP significou analisar a governança da coleta seletiva da cidade de Sáo Paulo, suas falhas e potenciais, bem como refletir sobre qual modelo se quer irradiar para a MMP nessa temática. No entanto, vale ressaltar duas limitaçóes do estudo aqui apresentado, o mapeamento de atores não foi exaustivo; e os recortes temporais e metodológicos adotados possibilitam a existência de atores que não tenham sido capturados no processo de mapeamento, exigindo novos mapeamentos no futuro.

Propóe-se neste artigo o início do desenvolvimento de uma agenda de pesquisa, que demandará estudos futuros. Recomenda-se a realização de entrevistas com os atores aqui observados, a fim de qualificar e quantificar as relaçóes entre os diversos atores, dando relevância e força às relaçóes formais e, principalmente, informais entre os atores. Outras possibilidades são: avançar na reconstrução do legado institucional e do histórico de legislaçóes da política de gestão de 
RSU; e no entendimento dos demais elementos que caracterizam os padróes de governança, possibilitando ampliar a compreensáo dos papéis dos atores na coleta seletiva, bem como compreender sua atuação nos processos de tomada de decisão. Destaca-se também a necessidade de replicação do estudo sobre os padróes de governança da coleta seletiva em outros municípios da MMP, outras regiôes e até outros países. Afinal, Marques (2013, p. 32) defende que "apenas a produção de estudos sobre outras cidades e políticas pode confirmar ou alterar esta descrição analítica" dos elementos que constituem os padrốes da governança das políticas urbanas.

\section{AGRADECIMENTOS}

As autoras agradecem aos pareceristas ad hoc do artigo que foram fundamentais para o aperfeiçoamento. Este artigo é fruto do fomento E-convênio 45169 e E-convênio 45219. Agradecimento especial aos pesquisadores e colaboradores do NOSS envolvidos no projeto Universalização da coleta seletiva na cidade de São Paulo.

\section{REFERÊNCIAS}

ABIKO, A. Serviços Públicos Urbanos. Texto Técnico, São Paulo, TT/PCC/10, Escola Politécnica da Universidade de São Paulo/Departamento de Engenharia de Construção Civil, 2011.

ARAÚJO, G.P. de; RODRIGUES, L.S.; DUNDER, B. D.; ZANIRATO, S.H. Planejamento e sustentabilidade urbana: uma análise do Plano de Ação da Macrometrópole Paulista. Revista Brasileira de Meio Ambiente, São Paulo, v.8, n.1, p. $100-112,2020$.

ASQUINO, A. A importância da Macrometrópole Paulista como escala de planejamento de infraestruturas de circulação e de transporte. Revista Brasileira de Estudos Urbanos e Regionais, Salvador, v. 12, n. 1, p. 83-98, 2010.

BARTHOLOMEU, D.B.; BRANCO, K.; E.H.; CAIXETA-FILHO, J.V. A logística de transporte dos resíduos sólidos domiciliares (RSD). In: BARTHOLOMEU, D.B.; CAIXETA-FILHO, J.V. (org.). Logística ambiental de resíduos sólidos. São Paulo: Atlas, 2011.p. 16-43.

BESEN, G.R.; SANTOS, K.L. ODS 12: Consumo e produção responsáveis. In: FREY, K.; TORRES, P.H.C.; JACOBI, P.R.; RAMOS, R.F. (org.). Objetivos do 
desenvolvimento sustentável: desafios para o planejamento e a governança ambiental na Macrometrópole Paulista. Santo André: Ed. da Universidade Federal do ABC, 2020. p.204-213. Disponível em: https://drive.google.com/file/d/19f_0QljFRctbYbQLW0DrPqW_gTtQSgE/view. Acesso em: 21 jan. 2021.

BRASIL. Lei no 12.305, de 02 de agosto de 2010. Institui a Política Nacional de Resíduos Sólidos; altera a Lei no 9.605, de 12 de fevereiro de 1998; e dá outras providências. Diário Oficial da Uniáo, Brasília, DF, 2010.

CAMPAGNONE, M.; LEITE, C.H. Plano de desenvolvimento urbano integrado para sustentabilidade na Região Metropolitana de São Paulo. In: GUNTHER, W. M. R.; PHILIPPI Jr, A. (org.). Planejamento urbano e políticas ambientais: métodos, instrumentos e experiências. São Paulo: Faculdade de Saúde Pública/USP, 2020. p.2-24.

CARNEIRO, C.B.L. Conselhos de políticas públicas: desafios para sua institucionalização. Revista de Administração Pública, São Paulo, v. 36, n. 2, p. 277-292, 2002. Disponível em: http://bibliotecadigital.fgv.br/ojs/index.php/rap/ article/view/6439. Acesso em: 26 fev. 2021.

CELLARD, A. A análise documental. In: POUPART, J. (org.). A pesquisa qualitativa: enfoques epidemiológicos e metodológicos. Petrópolis: Vozes, 2008. p. 295-316.

COMPANHIA AMBIENTAL DO ESTADO DE SÃO PAULO [CETESB]. Inventário estadual de resíduos sólidos urbanos: 2018. São Paulo: CETESB, 2019. (Série relatórios). Disponível em: https://cetesb.sp.gov.br/residuossolidos/wp-content/ uploads/sites/26/2019/06/Invent\%C3\%A1 rio-Estadual-de-Res\%C3\%ADduosS\%C3\%B3lidos-Urbanos-2018.pdf . Acesso em: 5 mar. 2021.

CONKE, L. S. A.; NASCIMENTO, E. P. Coleta seletiva nas pesquisas brasileiras: uma avaliação metodológica. Revista Brasileira de Gestáo Urbana, Curitiba, v. 10, n. 1, abril, 2018. Disponível em: https://doi.org/10.1590/2175-3369.010.001.AO14. Acesso em: 16 fev.2021.

DIANI, M. The concept of social movement. The Sociological Review, London, v. 40, n. 1, p. 1-25, 1992.

EMPRESA PAULISTA DE PLANEJAMENTO METROPOLITANO [EMPLASA]. Macrometrópole Paulista. São Paulo: EMPLASA, 2016. Disponível em: https:// emplasa.sp.gov.br/MMP. Acesso em: 05 mar. 2021.

EMPRESA PAULISTA DE PLANEJAMENTO METROPOLITANO [EMPLASA]. Caderno Macrometrópole Paulista. abr. 2012. Disponível em: https://cetesb.sp.gov. 
br/camaras-ambientais/wp-content/uploads/sites/21/2014/12/Macrometropole.pdf. Acesso em: 25 jan. 2022.

EMPRESA PAULISTA DE PLANEJAMENTO METROPOLITANO [EMPLASA]. Estudo da morfologia e da hierarquia funcional da rede urbana paulista e regionalização do Estado de São Paulo: Extrato. Documento 2. Resultados. São Paulo: SEADE, 2011.

FITZ, P.R. Cartografia básica. 2. ed. São Paulo: Oficina de texto, 2008.

FREY, K.; GUTBERLET, J.; RAMOS, R.F.; ANJOS, L.A.P. ODS 17: Parcerias e meios de implementação. In: FREY, K.; TORRES, P.H.C.; JACOBI, P.R.; RAMOS, R.F. (org.). Objetivos do desenvolvimento sustentável: desafios para o planejamento e a governança ambiental na Macrometrópole Paulista. Santo André: Ed. da Universidade Federal do ABC, 2020. p.274-288. Disponível em: https://drive.google.com/file/ d/19f_0QljFRct-bYbQLW0DrPqW_gTtQSgE/view. Acesso em: 21 jan. 2021.

FRUCHTERMAN, T.M.J.; REINGOLD, E.M. Graph drawing by force-directed placement. Software: Practice and Experience, Oxford, v.21, p. 1129-1164, 1991. Disponível em: https://doi.org/10.1002/spe.4380211102. Acesso em: 24 jan. 2022.

FUNDAÇÃO SISTEMA ESTADUAL DE ANÁLISE DE DADOS [SEADE]. Informaçóes dos municípios paulistas. São Paulo: SEADE, 2019. Disponível em: http://www.imp.seade.gov.br/frontend/\#/. Acesso em: 05 mar. 2021.

GAMBI, F. R.R. A Gestáo dos Resíduos Sólidos no Brasil: uma análise crítica das Parcerias Público-Privadas como arranjo emergente. 2018. Tese (Doutorado em Ciências Sociais) - Instituto de Filosofia e Ciências Humanas, Universidade Estadual de Campinas, Campinas, 2018.

GODOY, S. R. de. A economia política da limpeza urbana em São Paulo. Novos estudos CEBRAP, São Paulo, v. 35, n. 2, p. 55-76, 2016. Disponível em: http:// www.scielo.br/scielo.php?script=sci_arttext\&pid=S0101-33002016000200055\&lng= en\&nrm=iso. Acesso em: 24 mar. 2021.

GONÇALVES-DIAS, S. L. F. O desafio da Gestão de Resíduos Sólidos Urbanos. GV Executivo, São Paulo, v.11, n.1, p.16-20, jan./jun. 2012. Disponível em: https://rae. fgv.br/gv-executivo/vol11-num1-2012. Acesso em: 22 set. 2021.

GONÇALVES-DIAS, S.L.F et al. Universalizaçáo da coleta seletiva na cidade de São Paulo: Diagnóstico da coleta seletiva do município de São Paulo. São Paulo: Núcleo de Pesquisa em Organizaçóes Sociedade e Sustentabilidade (NOSS-USP), 2020 . 
GRIMBERG, E. Governança democrática e um novo paradigma de gestão de resíduos sólidos. São Paulo: Instituto Polis, 2005. Disponível em: https://polis.org. br/wp-content/uploads/2014/08/753.pdf. Acesso em: 31 mar. 2021.

HAAS, P.M. Introduction: Epistemic Communities and International Policy Coordination. International Organization, Cambridge, v. 46, n. 1, p. 1-35, 1992.

INSTITUTO BRASILEIRO DE GEOGRAFIA E ESTATÍSTICA [IBGE]. Áreas territoriais: Downloads. Brasília: IBGE, 2019a. Disponível em: https://www.ibge. gov.br/geociencias/organizacao-do-territorio/estrutura-territorial/15761-areas-dosmunicipios.html?edicao=27729\&t=downloads. Acesso em: 5 mar. 2021.

INSTITUTO BRASILEIRO DE GEOGRAFIA E ESTATÍSTICA [IBGE]. Produto Interno Bruto dos municípios: 2019. Brasília: IBGE, 2019b. Disponível em: https://www.ibge.gov.br/estatisticas/economicas/contas-nacionais/9088-produtointerno-bruto-dos-municipios.html?edicao=32575\&t=sobre. Acesso em: 5 mar. 2021.

INSTITUTO BRASILEIRO DE GEOGRAFIA E ESTATÍSTICA [IBGE]. Página inicial. Brasília: IBGE, 2019c. Disponível em: https://www.ibge.gov.br/. Acesso em: 5 mar. 2021.

INSTITUTO BRASILEIRO DE GEOGRAFIA E ESTATÍSTICA [IBGE]. Produto Interno Bruto dos municípios: 2018. Brasília: IBGE, 2018a. (Contas Nacionais, n.78). Disponível em: https://biblioteca.ibge.gov.br/visualizacao/livros/liv101776_ informativo.pdf. Acesso em: 5 mar. 2021.

INSTITUTO BRASILEIRO DE GEOGRAFIA E ESTATÍSTICA [IBGE]. Produto Interno Bruto dos municípios: Downloads. Brasília: IBGE, 2018b. Disponível em: https://www.ibge.gov.br/estatisticas/economicas/contas-nacionais/9088-produtointerno-bruto-dos-municipios. $h$ tml? edicao $=29720 \& \mathrm{t}=$ downloads. Acesso em: 5 mar. 2021.

INSTITUTO GEOGRÁFICO E CARTOGRÁfICO [ICG]. Página inicial. São Paulo, 2019. Disponível em: http://www.igc.sp.gov.br/. Acesso em: 5 mar. 2021.

KLEIN, F. B.; GONÇALVES-DIAS, S. L. F;; OLIVIERI, C. As transferências voluntárias do governo federal para a gestão de resíduos sólidos urbanos: um estudo da Região Metropolitana de São Paulo. Cadernos Metrópole, São Paulo, v. 22, n. 48, p. 457-478, 2020. Disponível em: https://doi.org/10.1590/2236-9996.2020-4806. Acesso em: 08 jul. 2021.

KUZ, A.; FALCO, M.; GIANDINI, R. Social network analysis: a practical case study. Computacion y Sistemas, Mexico, v.20, n.1, p. 89-10, 2016. 
LACERDA, L. F. S. Limpeza urbana em Sáo Paulo: uma análise da implementação da política entre 2002 e 2018. 2020. Dissertação (Mestrado em Ciências) - Escola de Artes, Ciências e Humanidades, Universidade de São Paulo, São Paulo, 2020.

LAVALlE, A.G. Sociedade Civil e Ecologias Organizacionais em Sáo Paulo e na Cidade do México: Uma Análise de Redes. Tese (Livre-docência em Ciência Política) - Faculdade de Filosofia, Letras e Ciências Humanas, Universidade de São Paulo, São Paulo, 2020.

LAVAllE, A.G.; VOIGT, J.; SERAFIM, L. O que Fazem os Conselhos e Quando o Fazem? Padróes Decisórios e o Debate dos Efeitos das Instituiçóes Participativas. Dados, Rio de Janeiro, v. 59, n. 3, p. 609-650, 2016. Disponível em: http://www. scielo.br/scielo.php?script=sci_arttext\&pid=S0011-52582016000300609\&lng=en \& nrm=iso. Acesso em: 25 fev. 2021.

LEITE, C. K. S.; LÓCCO, L. G. Actors, epistemic communities and policy change: analysis of the solid waste policy in Guarulhos (SP). Ambiente \& Sociedade, São Paulo, v. 23, 2020. Disponível em: https://doi.org/10.1590/18094422asoc20190024r2vu2020L6AO. Acesso em: 24 jan. 2022.

MARQUES, E. Governo, atores políticos e governança em políticas urbanas no Brasil e em São Paulo: conceitos para uma agenda futura. In: MENICUCCI, T.; GONTIJO, J. G. L. (org.). Gestáo e políticas públicas no cenário contemporâneo: tendências nacionais e internacionais. Rio de Janeiro: Ed. Fiocruz, 2016. p. 71-99.

MARQUES, E. Government, political actors and governance in urban policies in Brazil and São Paulo: concepts for a future research agenda. Brazilian Political Science Review, São Paulo, v. 7, p. 8-35, 2013. Disponível em: https:/www.scielo. br/scielo.php?pid=S1981-38212013000300001\&script=sci_arttext. Acesso em: 24 nov. 2020 .

MARTINELLI, M. Mapas da geografia e cartografia temática. 5. ed. São Paulo, SP: Contexto, 2010.

MENEZES, P.M.L.; FERNANDES, M.C. Roteiro de cartografia. São Paulo, SP: Oficina de Texto, 2013.

MOREIRA, A. M.M. et al. Percepção dos trabalhadores quanto aos perigos em centrais de triagem de recicláveis em São Paulo, Brasil. Ciência e Saúde Coletiva, Rio de Janeiro, v. 24, n.3, mar. 2019. Disponível em: https://doi.org/10.1590/141381232018243.01852017. Acesso em: 16 jul. 2021.

MOREIRA, S. V. Análise documental como método e como técnica. In: DUARTE, J.; BARROS, A. (org.). Métodos e técnicas de pesquisa em comunicação. São Paulo: Atlas, 2005. p. 269-279. 
MOVIMENTO NACIONAL DOS CATADORES DE MATERIAIS RECICLÁVEIS [MNCR]. Catadores ficam sem acesso ao material da Coleta Seletiva. São Paulo: MNCR, 2019. Disponível em: http://www.mncr.org.br/noticias/blog-sudeste/ catadores-ficam-sem-acesso-ao-material-da-coleta-seletiva. Acesso em: 04 jun. 2020.

NEGREIROS, R.; SANTOS, S.M.M; MIRANDA, Z.A.I. Nova escala de planejamento, investimento e governança na Macrometrópole Paulista. Revista Iberoamericana de Urbanismo, Barcelona, ano 7, n.12, 2015.

PARÉ, G.; CAMERON, A.F.; POBA-NZAOU, P.; TEMPLIER, M. A systematic assessment of rigor in information systems ranking-type Delphi studies. Information \& Management, Amsterdam, v. 50, n. 5, p. 207-217, 2013.

PASSOS, N. R. A. Apostila Gephi: um software open source de manipulação e visualizaçáo de grafos. 2013. Disponível em: https://www.academia.edu/34568301/ Apostila_Gephi_Um_software_open_source_de_manipula\%C3\%A7\%C3\%A3o_e_ visualiza\%C3\%A7\%C3\%A3o_de_grafos. Acesso em: 6 jul. 2021.

PASTERNAK, S.; BOGUS, L.M. Macrometrópole paulista: estrutura sócioocupacional e tipologia dos municípios - Mudanças na primeira década dos anos 2000. Revista Brasileira de Estudos Urbanos e Regionais, São Paulo, v. 21, n. 2, p. 431-450, 2019. Disponível em: https://doi.org/10.22296/2317-1529.2019v21n2p431. Acesso em: 24 jan. 2022.

ROMÃO, W.M. Entre a sociedade civil e a sociedade política: Participatory institutions in democratic Brazil. Novos Estudos CEBRAP, São Paulo, n. 87, p. 199-206, 2010.

RUTKOWSKI, J. E. Redes solidárias de catadores e gestão de resíduos sólidos. Tecnologia e Sociedade, Curitiba, v.9, n.18, 2013.

SÃO PAULO. Diretoria de Planejamento e Desenvolvimento. Coleta e Limpeza - SP: 2017-2019. São Paulo: Cidade de São Paulo, Subprefeituras, 2020.

SÃO PAUlO. Portal de Dados Abertos da Prefeitura de São Paulo. Coleta de Resíduos Sólidos Urbanos. São Paulo, 2019. Disponível em: http://dados.prefeitura. sp.gov.br/dataset/coleta-de-residuos-solidos-urbanos. Acesso em: 29 mar. 2021.

SÃO PAULO. Portaria Secretaria Municipal de Gestão - SMG No 10 de 30 de janeiro de 2018. Dá nova redação aos artigos $1^{\circ}, 2^{\circ}, 3^{\circ}, 4^{\circ}, 5^{\circ}, 6^{\circ}, 10,12,18,19$, Anexo I e Anexo II da Portaria no 34/SMG/2017. Legislaçáo Municipal, São Paulo, 2018. Disponível em: http://legislacao.prefeitura.sp.gov.br/leis/portaria-secretariamunicipal-de-gestao-smg-10-de-30-de-janeiro-de-2018. Acesso em: 20 jul. 2021. 
SÃO PAULO. Resolução no 109/AMLURB/2017. Reestrutura o Programa Socioambiental de Coleta Seletiva de Resíduos Recicláveis, e aprimora a Doação Social com Encargos para o Processamento de Resíduos Sólidos Domiciliares Secos provenientes do serviço público de coleta seletiva do Município de São Paulo. Diário Oficial da Cidade, São Paulo, SP, 2017a.

SÃO PAULO. Autoridade Municipal de Limpeza Urbana (AMLURB). Acesso à informaçáo. São Paulo, 2017b. Disponível em: https://www.prefeitura.sp.gov.br/ cidade/secretarias/subprefeituras/amlurb/acesso_a_informacao/index.php. Acesso em: 24 mar. 2021.

SÃO PAULO. Prefeitura Municipal. Comitê Intersecretarial para a Política Municipal de Resíduos Sólidos. Plano de Gestão Integrada de Resíduos Sólidos da Cidade de São Paulo. São Paulo, 2014a.

SÃO PAULO. Lei Municipal no 16.050, de 31 de julho de 2014. Aprova a Política de Desenvolvimento Urbano e o Plano Diretor Estratégico do Município de São Paulo e revoga a Lei no 13.430/2002. Diário Oficial da Cidade, São Paulo, SP, 2014b. Disponível em: https://gestaourbana.prefeitura.sp.gov.br/arquivos/PDE-SuplementoDOC/PDE_SUPLEMENTO-DOC.pdf. Acesso em: 10 jun. 2020.

SÃO PAULO (Estado). Lei Estadual no 12.300, de 16 de março de 2006. Institui a Política Estadual de Resíduos Sólidos e define princípios e diretrizes. Diário Oficial do Estado, São Paulo, SP, 2006. Disponível em: https://www.al.sp.gov.br/repositorio/ legislacao/lei/2006/lei-12300-16.03.2006.html. Acesso em: 29 mar. 2021.

SÃO PAULO. Lei Municipal no 13.478, de 30 de dezembro de 2002. Dispóe sobre a organização do Sistema de Limpeza Urbana do Município de São Paulo. Diário Oficial da Cidade, São Paulo, SP, 2002. Disponível em: https://www.prefeitura. sp.gov.br/cidade/secretarias/upload/arquivos/secretarias/financas/legislacao/Lei13478-2002.pdf. Acesso em: 15 jun. 2020.

TAVARES, J. Formação da Macrometrópole no Brasil: processo de urbanização e a constituição de uma região ganhadora. Ambiente \& Sociedade, São Paulo, v. 23, e 01221, 2020. Disponível em: http://www.scielo.br/scielo.php?script=sci_arttext \&pid=S1414-753X2020000100802\&lng=pt\&nrm=iso. Acesso em: 12 jan. 2021.

TEODÓSIO, A.S.S.; GONÇALVES-DIAS, S.L.F.; SANTOS, M.C.L. Reciclagem no Interstício das Relaçóes Intersetoriais: a Política Nacional de Resíduos Sólidos e os desafios para a inclusão social e produtiva dos catadores. In: SANTOS, M.C.L.; WALKER, S.; GONÇALVES-DIAS, S.L.F. (org.). Design, Resíduo \& Dignidade. São Paulo: Olhares, 2014. p. 231-268. 
TORRES, P.H.C.; RAMOS, R.F.; POLLACHI, A. A macrometropolizaçáo em São Paulo: reterritorialização, reescalonamento e a cidade-região. Cadernos Metrópole, São Paulo, v. 22, n. 47, p.103-122, 2020. Disponível em: https://doi.org/10.1590/ 2236-9996.2020-4705. Acesso em: 24 jan. 2022.

TRAVASSOS, L.R.F.C. et al. Heterogeneidade e fragmentação espacial na Macrometrópole Paulista: a produção de fronteiras e buracos. Ambiente \& Sociedade, São Paulo, v. 23, e01801, 2020. Disponível em: https:/www.scielo.br/j/ asoc/a/jJpYGfzFBbmBk6r38PtcRyv/?lang=pt\&format=pdf. Acesso em: 11 mar. 2021.

UNIVERSIDADE ESTADUAL PAULISTA [UNESP]. Tipos de revisão de literatura. Botucatu: Faculdade de Ciências Agronômicas, 2015. Disponível em: https://www.fca.unesp.br/\#!/biblioteca/normas-tecnicas/tipos-de-revisao-de-literatura. Acesso em: 23 fev. 2021.

WIRTH, I.G.; OLIVEIRA, C.B. A Política Nacional de Resíduos Sólidos e os Modelos de Gestâo. In: PEREIRA, B.C.J.; GOES, F.L. Catadores de materiais recicláveis: um encontro nacional. Rio de Janeiro: IPEA, 2016. p.217-245.

ZIONI, S.; TRAVASSOS, L.; MOMM, S.; LEONEL, A. A Macrometrópole Paulista e os desafios para o planejamento e gestáo territorial. In: TORRES, P. et al. (org.). Governança e Planejamento Ambiental: Adaptação e Políticas Públicas na Macrometrópole Paulista. Rio de Janeiro: Letra Capital, 2019. p.90-99.

Recebido em: 30 de março de 2021

Aprovado em: 16 de setembro de 2021 